OPEN ACCESS

Edited by:

Jon Pittman,

University of Manchester, UK

Reviewed by:

Wayne Versaw,

Texas A\&M University, USA Cornelia Spetea,

University of Gothenburg, Sweden

${ }^{*}$ Correspondence:

Ewa Młodzińska

ewa.mlodzinska@uwr.edu.pl

Specialty section:

This article was submitted to Plant Traffic and Transport,

a section of the journal

Frontiers in Plant Science

Received: 18 May 2016

Accepted: 27 July 2016

Published: 15 August 2016

Citation:

Młodzińska E and Zboińska M (2016)

Phosphate Uptake and Allocation -

A Closer Look at Arabidopsis thaliana

L. and Oryza sativa L.

Front. Plant Sci. 7:1198.

doi: 10.3389/fpls.2016.01198

\section{Phosphate Uptake and Allocation - A Closer Look at Arabidopsis thaliana L. and Oryza sativa L.}

\section{Ewa Młodzińska* and Magdalena Zboińska}

Department of Plant Molecular Physiology, Institute of Experimental Biology, University of Wrocław, Wrocław, Poland

This year marks the 20th anniversary of the discovery and characterization of the two Arabidopsis PHT1 genes encoding the phosphate transporter in Arabidopsis thaliana. So far, multiple inorganic phosphate (Pi) transporters have been described, and the molecular basis of Pi acquisition by plants has been well-characterized. These genes are involved in $\mathrm{Pi}$ acquisition, allocation, and/or signal transduction. This review summarizes how $\mathrm{Pi}$ is taken up by the roots and further distributed within two plants: $A$. thaliana and Oryza sativa L. by plasma membrane phosphate transporters PHT1 and PHO1 as well as by intracellular transporters: PHO1, PHT2, PHT3, PHT4, PHT5 (VPT1), SPX-MFS and phosphate translocators family. We also describe the role of the PHT1 transporters in mycorrhizal roots of rice as an adaptive strategy to cope with limited phosphate availability in soil.

Keywords: Arabidopsis thaliana, mycorrhiza, Oryza sativa, PHO1, phosphate translocators, phosphate transporters, phosphorus, transport

\section{INTRODUCTION}

Phosphorus is one of the macronutrients required by plants to grow and develop, but it is also one of the less accessible elements due to the very low solubility and poor mobility in soil solution as well as incorporation of phosphorus into organic compounds. It is estimated that about 20$80 \%$ of phosphorus in soils is present in organic matter mainly as phytic acid (Richardson, 1994; Schachtman et al., 1998). In addition, in acidic soils, phosphate forms insoluble precipitates with aluminum ( $\mathrm{Al})$ and iron $(\mathrm{Fe})$, while in alkaline soils $\mathrm{Pi}$ is reactive with calcium $(\mathrm{Ca})$ and magnesium (Mg; Raghothama, 1999; Hirsch et al., 2006). The primary source of phosphorus for plants is inorganic phosphate $(\mathrm{Pi})$, and at neutral $\mathrm{pH}$ the predominant form $\mathrm{H}_{2} \mathrm{PO}_{4}{ }^{-}$is transported into plant cells. Despite its quite low concentration in the soil solution (from 1 to $10 \mu \mathrm{M}$ ), the phosphate concentration in plant tissues is relatively high, about 5-20 mM (Raghothama, 1999; Hinsinger, 2001). This should not be surprising, because phosphorus is a fundamental element of essential biomolecules such as DNA, RNA, ATP, NADPH and membrane phospholipids. It also plays a crucial role for life-sustaining processes in plants including photosynthesis, respiration, and activation of proteins via phosphorylation (Poirier and Bucher, 2002). However, it was also reported that Pi concentration in the cytosol of Arabidopsis thaliana is only $60-80 \mu \mathrm{M}$ (Pratt et al., 2009).

To cope with Pi limitations in the environment, plants have evolved a range of physiological and morphological responses, which may enhance Pi acquisition (through symbiotic strategies, root architectural changes, extrusion of organic acids and acid phosphatases by roots (reviewed by Amtmann et al., 2006; Péret et al., 2011; Zhang Z. et al., 2014; Scheible and Rojas-Triana, 2015) and 
optimize internal Pi utilization. During $\mathrm{P}$ limitation some membrane phospholipids are partially replaced by galactolipids and sulfolipids (Nussaume et al., 2010; Siebers et al., 2015) Furthermore, under $\mathrm{Pi}$ starvation stress the remobilization of phosphorus from older leaves to younger organs was observed (Smith et al., 2003).

A distinctive, visible symptom of Pi starvation is anthocyanin accumulation in many plants, which leads to purpling leaves, stems and even roots. It is known that anthocyanin production is induced by phosphorus and nitrogen deficiency, as well as by other environmental stresses (salinity, cold, high light intensity), but the regulation of anthocyanins under environmental stresses remains unclear. A recent report suggested that anthocyanins play an important role in photoprotection of light-harvesting proteins in photosystems (Henry et al., 2012). Ito et al. (2015) attributed purpling in A. thaliana to the strigolactone signaling pathway and proposed that strigolactones modulate anthocyanin accumulation under low Pi conditions.

Twenty years ago, discovery of two Arabidopsis Pi transporters was a milestone in the plant molecular biology of phosphate nutrition (Muchhal et al., 1996). Significant progress has been made in deciphering the mechanism underlying action of $\mathrm{Pi}$ transporter networks in specific tissues, cells and organelles in response to phosphorus deficiency (described by Rausch and Bucher, 2002; Péret et al., 2011, 2014; Baker et al., 2015). The molecular mechanism regulating the expression of genes encoding phosphate transporters and signaling pathways in wild and cultivated plants including $A$. thaliana and rice has been reviewed comprehensively in recent articles (Chiou and Lin, 2011). Previous studies have established the co-existence of high and low-affinity phosphate transport systems in the plants roots (Nussaume et al., 2010). The high affinity transporters are plasma membrane proteins that are responsible for Pi uptake from soil. These proteins are encoded by members of the PHT1 (Phosphate Transporter) gene family and are proton-coupled $\mathrm{H}_{2} \mathrm{PO}_{4}^{-}$symporters. Movement of inorganic phosphate via PHT1 is driven by plasma membrane $\mathrm{H}^{+}$-ATPase (UllrichEberius et al., 1981). From roots Pi is loaded into xylem via the PHO1 transporters, where $\mathrm{Pi}$ is allocated to the aerial parts of plants (Poirier and Bucher, 2002; López-Arredondo et al., 2014). Organic forms of Pi such as nucleotides (ATP) and hexose phosphates are transported in phloem sap (Rausch and Bucher, 2002). To maintain Pi homeostasis at the cellular level plants store Pi in the vacuole, and recently VPT1 (Vacuolar Phosphate Transporter 1) has been characterized as a tonoplast influx transporter (Liu et al., 2015). The importance of controlling Pi level also extends to other organelles, including plastids, mitochondria and Golgi. Phosphate transport across the plastid, mitochondrial and Golgi membranes is mediated by proteins of the PHT2/4 and, PHT3 and PHT4 families, respectively (Rausch and Bucher, 2002). All proteins involved in acquisition and translocation of Pi between cell compartments will be described in further detail below. Thus, the present work synthesizes a more complete knowledge about phosphate transporters with special attention to the role of these proteins in two species: the dicot model plant $A$. thaliana L. and the important crop, as well as, monocot model plant Oryza sativa L.

\section{PLASMA MEMBRANE PHOSPHATE TRANSPORTERS}

As mentioned above, two types of transporters, PHT1 and PHO1, are responsible for phosphate uptake from soil and its further allocation to above-ground plant organs and between plant tissues. PHT1 proteins are the best described plant phosphate transporters. They belong to the family of phosphate: $\mathrm{H}^{+}$ symporters (PHS) within the major facilitator superfamily (MFS). The phosphate and proton transport stoichiometry is two to four $\mathrm{H}^{+}$ions for each Pi. PHT1 transporters have been identified only in plant and fungal cells, and in silico analyses have established that their secondary structures share a common building plan, with 12 putative transmembrane domains (TM) separated into two groups by a large hydrophilic loop between TM6 and TM7. N- and C-termini of the proteins are oriented toward the cytoplasm (Figure 1; Raghothama, 1999; Poirier and Bucher, 2002; Rausch and Bucher, 2002; Liu et al., 2011; Nussaume et al., 2011). The crystal structure of PiPT, a fungal high-affinity phosphate transporter from Piriformospora indica, confirms the predicted Pht1 topology and demonstrates that the structure is conserved among plants and fungi (Pedersen et al., 2013). PHT1 transporters have been described in a wide range of plant species (list of plant PTH transporters and their main features Supplementary Table S1), but they are best characterized for $A$. thaliana and O. sativa, whose genomes encode 9 and 13 PHT1s, respectively (Liu et al., 2011; Nussaume et al., 2011). Pht1 expression is induced or strongly up-regulated during P-deprivation, but some Pht1 genes are expressed regardless of the phosphate concentration in the environment (Mudge et al., 2002; Misson et al., 2004; Shin et al., 2004; Seo et al., 2008). It was also reported that PHT1 proteins can transport other solutes such as phosphite, arsenate, selenite, nitrate, sulfate, or chloride ions (Gu et al., 2016). Unfortunately, in many cases, functional analysis of particular PHT1 proteins is difficult because of their wide expression profile in most plant organs or complicated interpretation of results obtained from mutant analysis (discussed in more detail below).

Second type of transporters involved in phosphate distribution within the plant are $\mathrm{PHO} 1$ proteins. In contrast to $\mathrm{PHT} 1, \mathrm{PHO} 1$ belongs not to the MFS but to the SPX-EXS protein family (Secco et al., 2012). Beside transport properties PHO1 protein plays a role in signaling and participates in long distance (root-to-shoot) signal transduction cascade under Pi-deficiency. The topology of PHO1 from A. thaliana was recently analyzed - it consists of a long, cytoplasmic N-terminus harboring the tri-partite SPX domain, the cytoplasmic C-terminus with EXS domain and six membrane-spanning helices. The last two transmembrane helices are separated from the other four by a loop located in the cytoplasm and they are a part of the EXS domain (Figure 2). The EXS domain plays crucial role in PHO1 functioning - it is responsible for signaling capacity and Pi transporting activity of PHO1 (although it does not transport Pi by itself) as well as for proper protein localization in Golgi structures (Wege et al., 2016). PHO1 homologs are widely distributed in many organisms, including all land plants (bryophytes, lycophytes, gymnosperms, and angiosperms), fungi and animals (for example in Drosophila, 

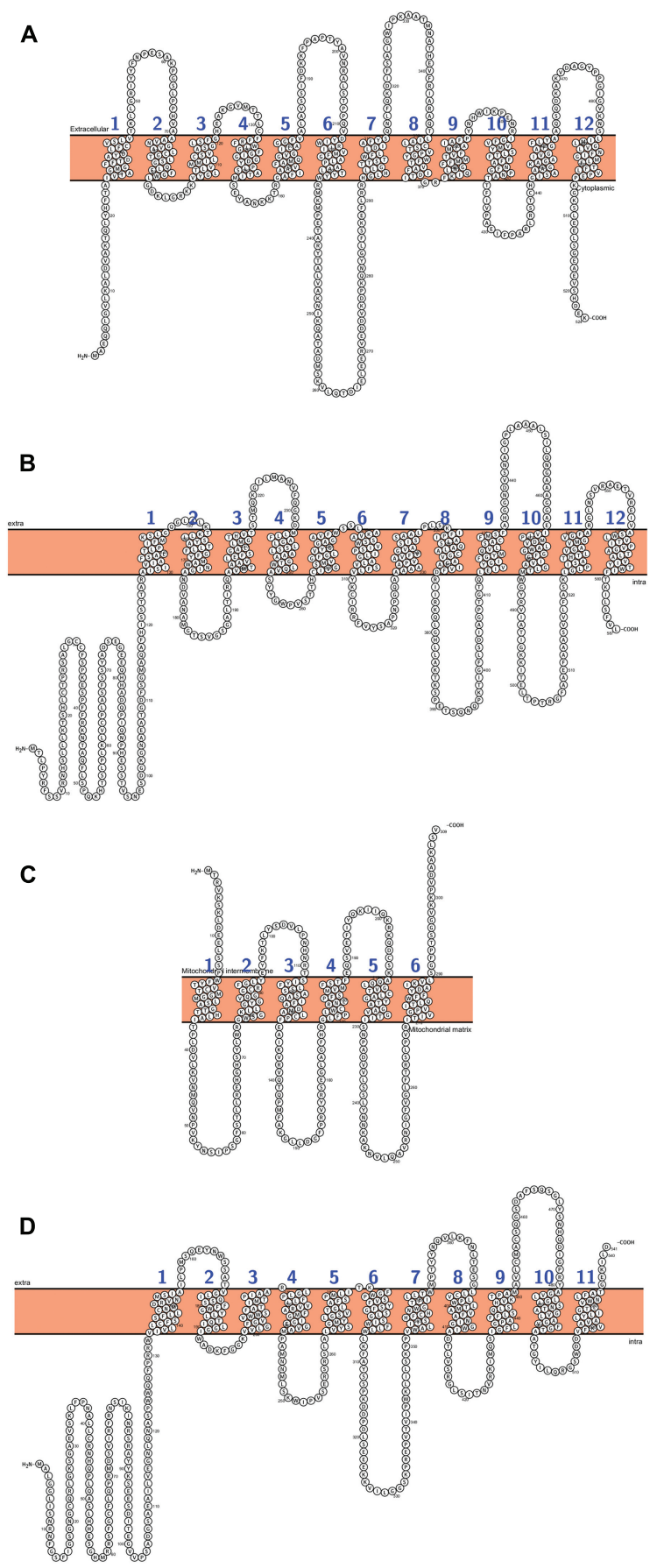

FIGURE 1 | Arabidopsis PHT proteins predicted topology: (A) AtPHT1;1, (B) AtPHT2;1, (C) AtPHT3;3, (D) AtPHT4;4. All figures were performed in Protter (Protter: interactive protein feature visualization and integration with experimental proteomic data. Omasits et al., 2014), protein sequences come from UniProt database.

Caenorhabditis elegans and mammals), but they have not been found in bacteria or in the unicellular green alga Chlamydomonas reinhardtii (Secco et al., 2012; Wege et al., 2016). Bioinformatics' analysis revealed that the Arabidopsis genome has 10 PHO1 homologs (PHO1;H1-PHO;H10), but to date the in Pi transport has been demonstrated only for PHO1 (Hamburger et al., 2002; Stefanovic et al., 2007, 2011; Arpat et al., 2012) and two PHO1 homologs, namely PHO1;H1 (Stefanovic et al., 2007) and $\mathrm{PHO} 1 ; \mathrm{H} 3$ (Khan et al., 2014). PHO1;H1 is able to compensate the loss of $\mathrm{PHO} 1$ function, whereas $\mathrm{PHO} 1 ; \mathrm{H} 3$ regulates $\mathrm{PHO} 1$ functioning under Zn-deficiency (Khan et al., 2014). The rice PHO1 family consist of three members: OsPHO1;1, OsPHO1;2 and OsPHO1;3, but only OsPHO1;2 seems to play a similar role to PHO1 from A. thaliana (Secco et al., 2010).

\section{ROLE OF PHT1 IN DIRECT PHOSPHATE UPTAKE FROM SOIL}

Plants can take up phosphate directly from the soil or indirectly, form a mycorrhizal association, through the exchange of carbohydrates produced during photosynthesis for Pi released from fungus mycelium (Rausch and Bucher, 2002; Javot et al., 2007b). The direct strategy of phosphate uptake involves the PHT1 transporters present in the rhizodermis (especially in trichoblast cells) and, to a lesser extent, in the cortical cells. In Arabidopsis, eight of the nine PHT1 are expressed in root tissues (Mudge et al., 2002; Shin et al., 2004; Lapis-Gaza et al., 2014), while in rice root the transcripts of all 13 OsPHT1 were detected. Although, results obtained from different genetic experiments are sometimes discordant (Paszkowski et al., 2002; Seo et al., 2008; Yang et al., 2012), mutant analysis established that in phosphate uptake four transporters in A. thaliana (AtPHT1;1 AtPHT1;4; Ayadi et al., 2015) and at least six PHT1 in O. sativa (OsPHT1;1/2/4/6/8/9/10; Seo et al., 2008; Ai et al., 2009; Jia et al., 2011; Wang X.F. et al., 2014; Ye et al., 2015) are principally involved.

Comprehensive analysis of AtPHT1 genes expression in Arabidopsis roots under high $\mathrm{Pi}$ supply has shown the highest activity of AtPHT1;1 promoter (Mudge et al., 2002). Nerveless, the transcripts of AtPHT1;2-AtPHT1;4 were also detectable in the phosphate-fed roots. On the other hand, in Pi-deprived plants the AtPHT1;1 mRNA level was only slightly enhanced (3to 4-fold), while the expression of other genes from AtPHT1 family increased much more distinctly (25- to 70-fold; Ayadi et al., 2015). Reporter genes (GUS or GFP) expression driven by the AtPHT1;1 promoter revealed its localization in rhizodermis, especially in root hairs, but also in the lateral root caps, columella cells and, at relatively weak level, in cortical cells of the root hair zone (Mudge et al., 2002). Similarly, AtPHT1;2 was expressed in trichoblast cells and in the cortex of older parts of root, the AtPHT1;3 in trichoblasts of lateral roots and in epidermis near the root tip of the main root, as well as in pericycle cells of the main root (Mudge et al., 2002), while AtPHT1;4 in the epidermis, cortex, stele, and root tips (Mudge et al., 2002; Misson et al., 2004). These results suggest that AtPHT1;1, AtPHT1;2, AtPHT1;3, and AtPHT1;4 may have similar, partially overlapping functions (Mudge et al., 2002), which was later confirmed experimentally (Misson et al., 2004; Shin et al., 2004; Ayadi et al., 2015). Namely, it was shown that under high Pi supply the phosphate uptake by the atpht1;1 insertion mutant was reduced 


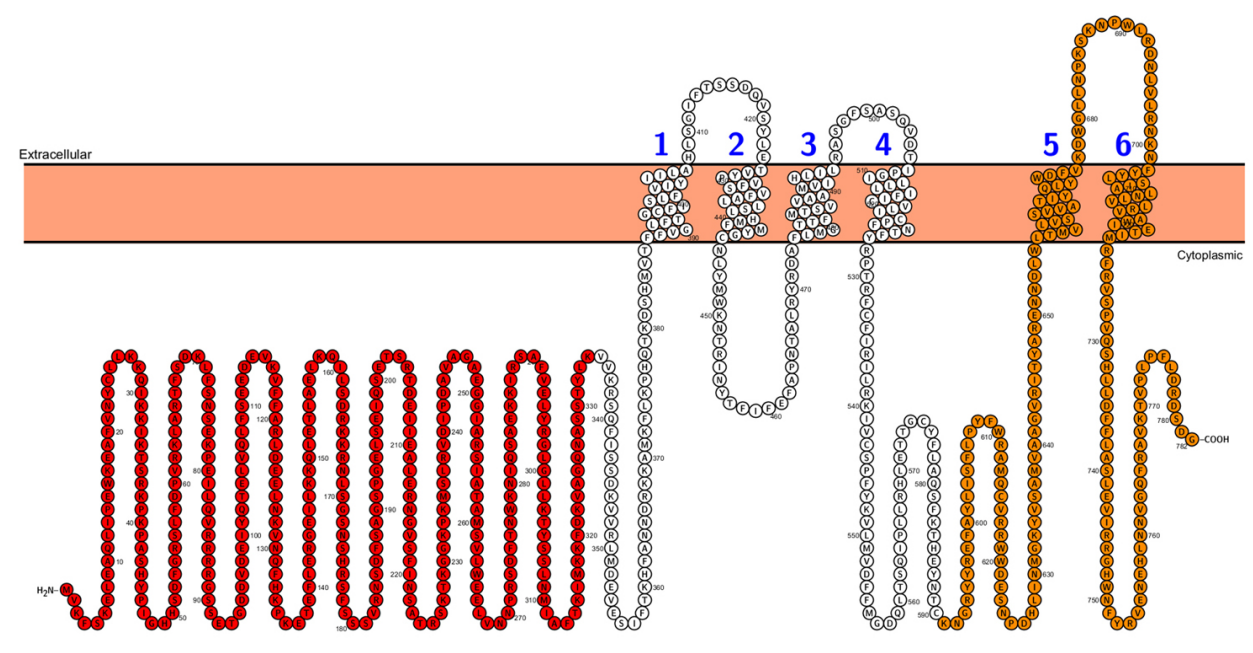

FIGURE 2 | Arabidopsis PHO1 protein predicted topology. Cytoplasmic N-terminus SPX domain is designed in red color, and the C-terminus with EXS domain is designed in orange color. Figure was performed in Protter (Protter: interactive protein feature visualization and integration with experimental proteomic data. Omasits et al., 2014), protein sequence comes from UniProt database.

to around $60 \%$, while in double mutant atpht $1 ; 1 \Delta 4 \Delta$ to around $30 \%$ of the wild type rate (Shin et al., 2004). Such data suggests the main role of AtPHT1;1 in phosphate uptake by Arabidopsis roots at high $\mathrm{Pi}$. Contrariwise, in P-starved plants, the predominant role in $\mathrm{Pi}$ acquisition plays AtPHT1;4, which is responsible for uptake of around $40-48 \%$ of $\mathrm{Pi}$, while AtPHT1;1 contributes only in 15-20\% of uptake and AtPHT1;2 and AtPHT1;3 together take up around 30\% of Pi (Misson et al., 2004; Shin et al., 2004; Ayadi et al., 2015). Besides four main transporters (AtPHT1;2 AtPHT1;4) the role of other AtPHT1 members in Pi acquisition cannot be ruled out. For example, the atpht1;5 mutant exhibits moderate tolerance of arsenate ( $\mathrm{Pi}$ structural analog, toxic for plants, which is transported via PHT), suggesting a possible role of AtPHT1;5 in Pi uptake (Nagarajan et al., 2011).

Reduced Pi uptake in knockout or knockdown (RNAi) lines and enhanced uptake in overexpressing lines has been demonstrated for rice OsPHT1 transporters (also named OsPT), including OsPHT1;1 (Sun et al., 2012), OsPHT1;2 (Liu et al., 2010), OsPHT1;4 (Ye et al., 2015; Zhang et al., 2015), OsPHT1;6 (Zhang F. et al., 2014), OsPHT1;8 (Jia et al., 2011), OsPHT1;9, and OsPHT1;10 (Wang X.F. et al., 2014). Among them only OsPHT1;1 is constitutively expressed, while the rest is remarkably upregulated under Pi deprivation (Seo et al., 2008; Wang X.F. et al., 2014). Only one protein from OsPHT1 family, the OsPHT1;2, is a low-affinity transporter (Ai et al., 2009). Interestingly, most of OsPHT1s do not exhibit the tissue-specific expression, but they are expressed ubiquitously in various root tissues and in some other plant organs. Therefore, it is reasonable to conclude that these transporters play probably a broad role in both, the phosphate acquisition and its translocation (Seo et al., 2008; Ai et al., 2009; Jia et al., 2011; Sun et al., 2012; Wang X.F. et al., 2014; Zhang F. et al., 2014; Ye et al., 2015; Zhang et al., 2015). Furthermore, tissues-specific expression of some OsPHT1s depends on developmental stage of plant. Good example is OsPHT1;4 whose promoter activity was detected in all tissues of embryonic root (Zhang et al., 2015), while in mature plants growing under normal $\mathrm{Pi}$ it was found only in the exodermis the outer layer of cortical cells which is involved in regulation of radial flow of water and ions in the root. During a long Pistarvation, OsPHT1;4 starts to be expressed in the cortical cells, which suggest its involvement in symplastic Pi transport under this stress condition (Ye et al., 2015). Taking into account all these data and the fact that overexpression or mutation of one of the PHT1s may alter the expression of the others (Jia et al., 2011; Lapis-Gaza et al., 2014; Ye et al., 2015), it is very difficult to ascertain which of these transporters are crucial for Pi uptake and distribution.

\section{ROLE OF PHT1 IN PHOSPHATE TRANSPORT IN MYCORRHIZAL ROOTS}

It is estimated that $90 \%$ of terrestrial plant species can be colonized by mycorrhizal fungi (Smith and Smith, 2012) and more than $80 \%$ of vascular plants, including main crops, form arbuscular mycorrhizae (Karandashov and Bucher, 2005; Javot et al., 2007b). Whereas A. thaliana belongs to the minority of plant species that do not form mycorrhizal associations (Vance, 2008), O. sativa is an arbuscular mycorrhizal (AM) plant (Yang et al., 2012).

Arbuscular mycorrhizal fungi belong to the phylum Glomeromycota. Their hyphae penetrate the plant roots, enter cortical cells and inside each cell form hyphal coils or a heavily branched structure named an arbuscule (AM). Arbuscules or hyphal coils do not disrupt the integrity of the plant plasma membrane but through its invagination form intracellular spaces. Fungus infection alters the structure of cell plasma membrane allowing the growth of arbuscule/hyphal coils and creates a periarbuscular membrane (named the perihyphal membrane in the case of hyphal coil formation). The interface 
between this membrane and the hyphal plasma membrane is the place of nutrient exchange between symbiotic partners (Bucher, 2007; Javot et al., 2007b; Gu et al., 2011; Smith and Smith, 2012).

Beside other positive aspects of AM formation, such as protection against abiotic stresses and pathogens as well as improving of water acquisition from the soil, the best-known function of this type of mycorrhiza is the contribution of the fungus to plant P nutrition (Jeffries et al., 2003; Smith and Smith, 2012). On the other hand, Pi status of the plant is the main factor regulating the colonization process, delivery of sugars to hypha and symbiosis formation (Javot et al., 2007b; Gu et al., 2011). In plants inoculated with AM fungi two pathways of $\mathrm{Pi}$ uptake coexist. The first is the direct pathway from the soil through the membranes of root epidermis cells, involving the above-described PHT1 transporters. The second, indirect pathway via fungal mycelium engages plant PHT1 transporters located in the periarbuscular membrane at the arbuscule branch domain, which are specifically induced or upregulated by AM formation (Karandashov and Bucher, 2005; Kobea and Hata, 2010; Gu et al., 2011). Expression of these PHT1 transporters is closely correlated with the degree of root colonization and, at the single cell level, with the arbuscule formation and collapse (Paszkowski et al., 2002; Kobea and Hata, 2010). Physiological studies on several plant species (flax, tomato, rice, Medicago truncatula) have shown that under low $\mathrm{Pi}$ concentrations the mycorrhizal pathway is dominant (Yang et al., 2012). This is not surprising, because mycorrhizal formation is often accompanied with diminished expression of PHT1 involved in the direct Pi uptake pathway (Javot et al., 2007b). Among rice PHT1 genes, OsPHT1;11 (Paszkowski et al., 2002; Kobea and Hata, 2010; Yang et al., 2012) and OsPHT1;13 (Güimil et al., 2005; Yang et al., 2012) were proposed to be involved in the symbiotic Pi uptake route.

In fact, in most plant species forming mycorrhizal symbioses at least one mycorrhizal specific or upregulated PHT1 gene has been discovered. What is more, phylogenetic analysis of PHT1 protein sequences showed that AM-associated PHT1s form their own lineage, which is evolutionarily distant from non-AM-associated PHT1s. Within this lineage several groups can be distinguished (Javot et al., 2007b; Yang et al., 2012). For example, OsPHT1;11 homologs are common among monocots and dicots and are evolutionarily older, being closely related to PHT1 transporters from the ancient plants Physcomitrella patens (bryophyte) and Selaginella moellendorffi (lycophyte), when OsPHT1;13 orthologs are conserved in monocotyledons, but not in dicotyledons (Yang et al., 2012).

OsPHT1;11 and OsPHT1;13 expression is undetectable in nonmycorrhizal roots but is induced after rice inoculation with Glomus intraradices or Gigaspora rosea (Yang et al., 2012). An increase of OsPHT1;11 transcript level is significantly higher than OsPHT1;13, but the overall expression profiles of these two genes are similar. It was shown that promoters of both genes are specifically active in cortical cells containing arbuscules, although OsPHT1;13-GUS staining is weaker than OsPHT1;11GUS staining. Mutation or downregulation of either OsPHT1;11 or OsPHT1;13 by RNAi causes strong reduction of fungal colonization and arbuscule development, but the phenotype of plants with altered expression of OsPHT1;11 is definitely stronger. Interestingly, beside many similarities between these genes, their function in AM symbiosis establishment seems to be different. Mutations of both genes have no impact on $\mathrm{Pi}$ transport after mock inoculation, but uptake of ${ }^{33} \mathrm{Pi}$ by osph1;11 or OsPHT1;11 RNAi lines inoculated with $G$. intraradices dramatically impaired relative to WT rice, whereas osph1;13 and OsPHT1;13 RNAi plants infected by AM fungus exhibit ${ }^{33} \mathrm{Pi}$ acquisition similar to the uninfected plants. Moreover, expression of OsPHT1;13 in yeast pam2 mutant defected in Pi uptake did not complements yeast sensitivity to phosphate deprivation. These results strongly implicate that OsPHT1;13 operates as a mycorrhizal sensor rather than a transporter directly involved in Pi translocation through the periarbuscular membrane (Yang et al., 2012). Comparable sensor function was shown for AsPHT1;1 (AsPT1) from Astragalus sinicus. However, contrariwise to OsPHT1;13 this protein exhibits also transporting activity (Xie et al., 2013). Thus, it is highly feasible that both proteins (OsPHT1;13 and AsPHT1;1) can be classified as transceptors, the class of proteins combining receptor and transporter functions. As we know, during evolution some transceptor proteins may lose their transporting abilities (Popova et al., 2010; Gojon et al., 2011).

Although, some authors described OsPHT1;11 and OsPHT1;13 as genes specifically induced by mycorrhizal formation (Yang et al., 2012), other studies confirmed OsPHT1;13 expression in the non-colonized roots subjected to low or high Pi supply (Glassop et al., 2007). Furthermore, comprehensive microarray analysis of OsPHT1;13 expression in inoculated rice showed different levels of its transcript in vegetable and generative parts of in the rice plant at different lifecycle stages (Liu et al., 2011). The physiological functions of both proteins in the leaves and flowers of uninfected rice remain unclear, but this finding is not a rare occurrence. Maize $\mathrm{ZmPHT1;6,}$ Brachypodium distachyon BdPHT1;7, tomato LePHT1;5 (Yang et al., 2012) and soybean GmPHT1;7 (Inoue et al., 2014) genes specifically induced in roots by AM formation, are also expressed in above-ground plant organs as well as in asymbiotic roots.

\section{ROLE OF PHT1 TRANSPORTERS IN ROOT DEVELOPMENT}

The impact of PHT1 on lateral root development has been proposed by several authors. Misson et al. (2004) observed strong AtPHT1;4-GUS activity in the central cylinder of the main root at the lateral root emerging point. At the beginning of the root branching, GUS staining was also strong in the central cylinder of lateral roots but later, during root emergence, it disappeared and, at the same time, evolved in the lateral root epidermis. Such expression profile was plausibly related to the role of AtPHT1;4 in $\mathrm{Pi}$ transport to the newly forming roots, and this process terminates when the young roots start to absorb phosphate from the soil (Misson et al., 2004). AtPHT1;4 seems, however, not to be crucial for the lateral root formation, as its mutation has no influence on this process. What is more, the local input of high Pi distinctly induced the lateral root elongation of the double pht1;1 $\Delta 4 \Delta$ mutant (Shin et al., 2004). The main function in 
development of lateral root in $O$. sativa has been proposed for OSPHT1;2, OsPHT1;6 (Ai et al., 2009) and OsPHT1;8 (Jia et al., 2011), according to their high promoter-GUS activities in the lateral root primordia.

In A. thaliana, overexpression of AtPHT1;5 causes increased root hair density and length, and reduced primary root growth, irrespectively of the phosphate regimen (Nagarajan et al., 2011). Similarly, strong root hair proliferation under P-sufficient conditions occurred in OsPHT1;1 overexpressing rice and in RNAi (OsPHT1;1-Ri) transgenic plants (Sun et al., 2012). These changes in root architecture were characteristic for P-starved plants and lead to the development of shallow but strongly branching root system with dense root hairs (Lambers et al., 2006). Above alterations in root architecture were perhaps not simply provoked by a low Pi concentration in roots but rather by the differential distribution of Pi between plant tissues/organs or by disturbances in the complex network of signaling pathways of P-deprivation, phytohormones, or other signaling molecules (Nagarajan et al., 2011; Sun et al., 2012). Similar, local modifications of lateral root formation could be promoted by patches rich in other nutrients, like nitrate and ammonium (Lima et al., 2010). Root system alterations in response to the local availability of mineral nitrogen forms were described for atamt $1 ; 3$ mutant with defected ammonium transporter (Lima et al., 2010) as well as for atnrt1;1 mutant disrupted in nitrate transporter (Krouk et al., 2010). Experimental data indicated that in both cases the mutation affects the perception/signaling mechanism (Krouk et al., 2010; Lima et al., 2010). Furthermore, AtNRT1;1 participates directly in lateral root growth by regulation of auxin flow out of the primordium tip, which is dependent on the soil nitrate content (Krouk et al., 2010). Recent investigations have demonstrated the capability of the nitrate transporter (NRT) family members to transport other plant hormones (abscisic acid, gibberellin, jasmonoyl-isoleucine), so it seems to be a general characteristic of them (Chiba et al., 2015). As NRT, likewise PHT, belongs to the Major Facilitator Superfamily (Williams and Miller, 2001), it would be reasonable to investigate pht 1 mutants more precisely, in the context of root formation and phytohormones transport. Among PHT proteins, the role in Pi sensing and regulation of early lateral root branching was also proposed for two Pi transporters: MtPHT1;4 (MtPT4) and LjPHT1;4 (LjPT4). Expression of MtPHT1;4 and LjPHT1;4 genes occur in arbusculated cells in AM root. However, both transcripts were also found in the root tips of non-mycorrhizal roots. Expression impairment of all P-starvation marker genes in $m t / l j p h t 1 ; 4$ as well as $m t / l j t i r 1$ mutants have might regulate the lateral root formation in similar manner as AtNRT1;1 transceptor (Volpe et al., 2016).

\section{PHOSPHATE ALLOCATION FROM ROOT TO SHOOT}

After uptake into the root cells $\mathrm{Pi}$ is subsequently used to synthesize P-containing compounds such as ATP or phospholipids, or can enter the vacuole, where it is stored (Figure 3). Nevertheless, the main fraction of phosphate is transferred toward the central cylinder, then released into xylem vessels and allocated to the stem, leaves, flowers, and seeds (Rausch and Bucher, 2002). At first, AtPHT1;9 and AtPHT1;8 were described as transporters involved in Pi uptake (Remy et al., 2012), but this hypothesis has been abandoned following results showing the role of both proteins in phosphate translocation from root to shoot, but not in phosphate acquisition directly from soil solution (Lapis-Gaza et al., 2014). It was also shown that these two proteins cooperate in phosphate translocation with PHO1 (Hamburger et al., 2002) and possibly with AtPHT1;3 and AtPHT1;4 (Mudge et al., 2002).

The pho1 mutant of $A$. thaliana was first described in Poirier et al. (1991) as a mutant with disrupted Pi transfer into the xylem but normal phosphate uptake and its movement through the xylem system. Mutation of PHO1 causes a strong P-starvation response with stunted growth and reduction of Pi content in shoots, to less than 5\% compared to WT (Poirier et al., 1991). Later, the GUS method revealed that the $\mathrm{PHO1}$ promoter is active in the lower part of the hypocotyl, in the stele of roots (including xylem parenchymal cells and pericyclic) as well as in the endodermal cells adjacent to the protoxylem. Analogous to endodermis, pericyclic cells next to the protoxylem were stained more strongly than pericyclic cells farther away. No GUS staining was detected in the root tip or elongation zone (Hamburger et al., 2002).

AtPHO1 expression in heterologous systems (yeast cells and Xenopus oocytes) have not confirmed the transporting activity of encoded protein (Hamburger et al., 2002). PHO1 transport activity was proved 9 years later, in Arabidopsis PHO1 overexpressing lines, by Stefanovic et al. (2011). They showed that constitutive PHO1 overexpression in leaves leads to more than 100-fold higher Pi concentration in guttation fluid (xylem sap), with a larger increase of Pi content (140-fold) in plants with stronger $\mathrm{PHO1}$ overexpression than in plants with weaker PHO1 expression (100-fold increase; Stefanovic et al., 2011). A similar result, indicating the transporting role of $\mathrm{PHO1}$, was obtained using Arabidopsis transgenic plants with $\mathrm{PHO}$ under the control of an estradiol-inducible promoter (Arpat et al., 2012). All considered, the PHO1 subcellular localization results were rather surprising: PHO-GFP predominantly co-localized with the Golgi/trans-Golgi (Arpat et al., 2012), endoplasmic reticulum, and occasionally with endosomal markers (Liu et al., 2012). Moreover, this localization was associated with Pi export activity of PHO1. Nevertheless, in some circumstances, including a high Pi concentration in the cytoplasm, PHO1 could be partially redistributed to the plasma membrane, which leads to the conclusion that $\mathrm{PHO} 1$ relocalization between cell membranes is an element of the phosphate homeostasis sustaining system (Arpat et al., 2012). Likewise, the dual localization profile, in the plasma membrane and ER, exhibits for example the $\mathrm{K}^{+}$ channel TPK4 (Sharma et al., 2013). Other possibility is PHO1 engagement in Pi loading into endosomal vesicles and Pi export via exocytosis (Arpat et al., 2012).

The second PHO1 protein involved in Pi loading into the xylem is $\mathrm{PHO} 1 ; \mathrm{H1}$. PHO1;H1 is expressed in the vascular system of root and shoot, and is able to compensate the loss of PHO1. Although pho1; $h 1$ does not express any P-starvation hallmarks, 


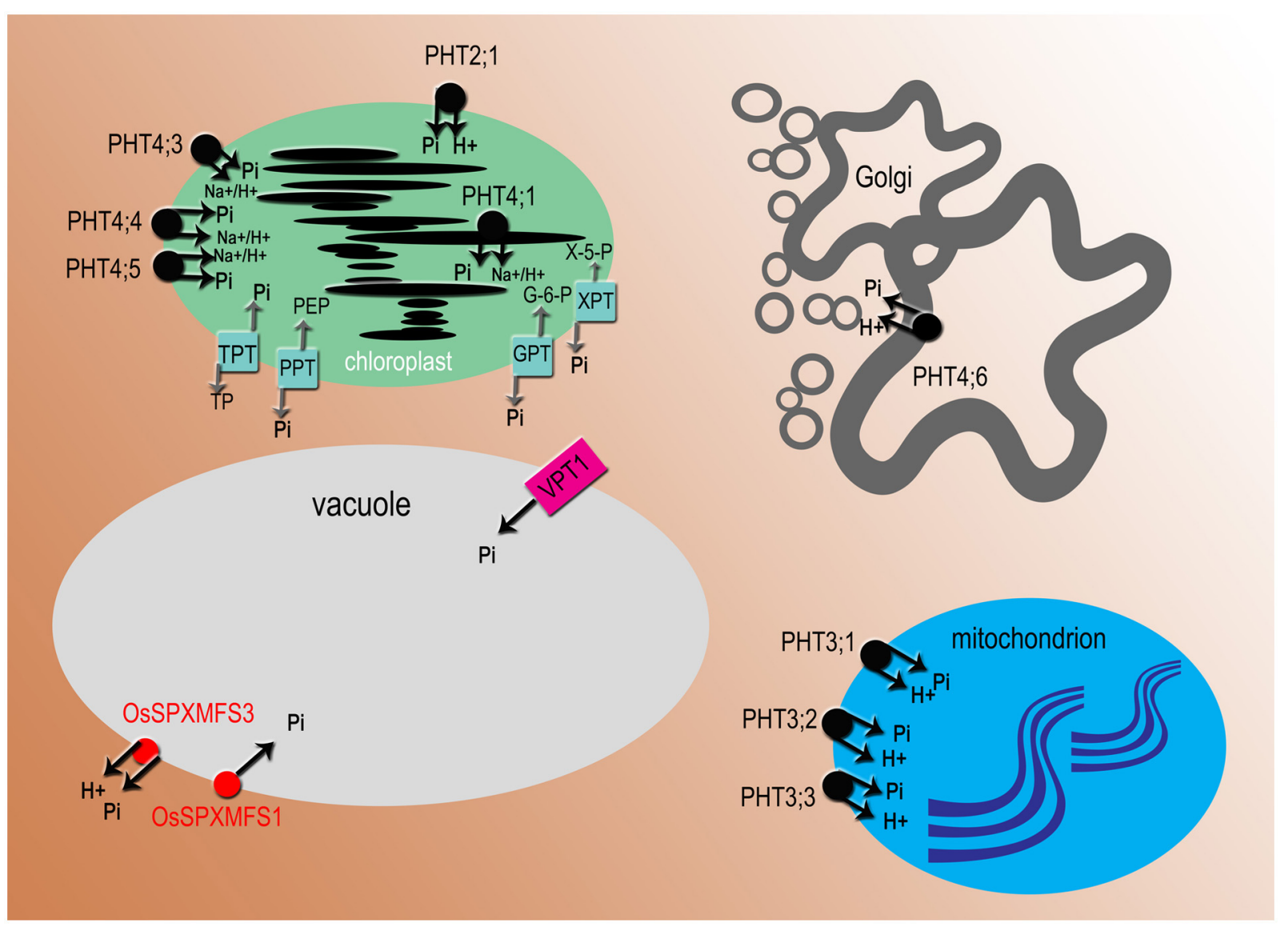

FIGURE 3 | Subcellular localization of phosphate transporters and translocators. All names in black are for Arabidopsis proteins, in red for Oryza sativa. PHT2, PHT3, and OsSPX-MFS3 are proton-coupled Pi transporters, PHT4 transporters mediate $\mathrm{H}^{+}$or $\mathrm{Na}^{+}$dependent phosphate transport, VPT1 (PHT5;1) and OsSPX-MFS1 acts as Pi channel. PHT2, 3, 4 Phosphate Transporter 2, 3, 4; VPT1 (PHT5;1), Vacuolar Phosphate Transporter1 (Phosphate Transporter5;1); OsSPX-MFS, O. sativa (SPX)-Major Facility Superfamily. There are four types of Pi transloclators: TPT, triose-phosphate/phosphate translocator; PPT, phosphoenolpyruvate/phosphate translocator; GPT, glucose 6-phosphate/phosphate translocator; XPT, xylulose-5-phosphate translocator.

the double mutant phol/phol;h1 shows stronger phenotypic features than pho1, indicating that both proteins are involved in $\mathrm{Pi}$ influx into the xylem. Interestingly, $\mathrm{PHO} 1$ and $\mathrm{PHO} ; \mathrm{H1}$ seem to be regulated in various ways what may be connected with Arabidopsis flexibility during P-deficient stress (Stefanovic et al., 2007). Other Arabidopsis PHO1 genes whose transcripts are localized in the root tissues were $\mathrm{PHO} ; \mathrm{H} 4$ and $\mathrm{H} 10$ in epidermal and cortical cells, $H 5$ and $H 7$ in the root tip, and $H 3, H 3$, H5, H7, and H8 in the vascular cylinder (Wang et al., 2004). Among three rice $\mathrm{PHO} 1$ proteins only OsPHO1;2 plays a role similar to PHO1, and ospho1;2 mutation leads to the reduction of phosphate content in shoot, phosphate over-accumulation in root tissues, and altered growth of plants (Secco et al., 2010).

AtPHT1;8 and AtPHT1;9 are both expressed in roots, more strongly during P-deficient than in P-replete conditions (Misson et al., 2004; Shin et al., 2004; Remy et al., 2012; Lapis-Gaza et al., 2014). Atpht1;8 and atpht1;9 mutant lines are characterized by the same uptake rate as WT plants and much slower short-term $\mathrm{Pi}$ accumulation in the shoot than atpht1;1 plants. Moreover, they are expressed mainly in the endodermis and xylem of the meristematic zone and throughout the root in xylem pole pericycle cells. These observations suggest that AtPht1;8 and AtPHT1;9 might regulate Pi translocation into the xylem. It is also proposed that in the meristematic region AtPHT1;9 works in the root layer closer toward the epidermis, probably in the endodermis and/or pericycle, whereas AtPHT1;8 acts deeper, in pericycle or xylem cells (Lapis-Gaza et al., 2014). Taking into account that AtPHT1;3 shows an expression pattern partially similar to AtPHT1;8 and AtPHT1;9 in pericycle cells along the root (Mudge et al., 2002), and that AtPHT1;4 can be expressed in the stele of the main root at the secondary root branching points (Misson et al., 2004), probably in the cells interior to the pericycle strand (Mudge et al., 2002), it can be suggested that AtPHT1;3 and AtPHT1;4 may help AtPHT1;8 and AtPHT1;9 to play their roles. On the other hand, these transporters can potentially have a scavenging role and reabsorb Pi leaking from xylem vessels (Mudge et al., 2002). Additionally, as has been suggested for AtPHT1;4, they may participate in the lateral root emergence (Misson et al., 2004). 
Among rice PHT1 members, OsPHT1;2 was chiefly proposed to mediate $\mathrm{Pi}$ transfer into the root vasculature, based on its low affinity to phosphate and spatial localization in the central cylinder of the lateral and main roots, but not in the endodermis, cortex, or epidermis. Reduced phosphate content in the shoot of OsPHT1;2-RNAi transgenic plants (Ai et al., 2009), and definitely higher Pi concentration in the shoots than in the roots of OsPHT1;2 overexpressing line under P-sufficient conditions (Liu et al., 2010), compared to wild type, support this conclusion. Later research focused on the function of OsPHT1;2 in selenite uptake, providing evidence that OsPHT1;2 mRNA is present in the rhizodermis of primary roots under P-deprived conditions. This discovery could be explained by developmental stage-depending expression of this gene, or by differences between rice cultivars used for in the study, but may also underline the additional role of OsPHT1;2 in Pi uptake (Zhang L. et al., 2014). OsPHT1;2 is probably supported by other OsPHT1 members, expression of which was detected in vascular tissue in the root: OsPHT1;1 (Sun et al., 2012), OsPHT1;4 (Zhang et al., 2015), OsPHT1;6 (Ai et al., 2009; Zhang F. et al., 2014) and OsPHT1;8 (Jia et al., 2011). Functional analysis of rice overexpressing OsPHT1;1 showed no significant differences in $\mathrm{Pi}$ translocation to the shoot when rice was growing at a low $\mathrm{Pi}$ concentration, but under high Pi supply plants accumulated nearly two times more $\mathrm{Pi}$ in the xylem sap of stems (Sun et al., 2012). Respectively, higher or lower ${ }^{33} \mathrm{Pi}$ concentration in xylem sap, under both P-deficient and P-sufficient conditions, was also observed in OsPHT1;4 overexpressing, ospht1;4 and OsPHT1;4 RNAi rice. These plants were also characterized by altered shoot/root content of ${ }^{33} \mathrm{Pi}$ (Zhang et al., 2015). Similarly, monitoring of ${ }^{33} \mathrm{P}$-labeled $\mathrm{Pi}$ distribution demonstrated a higher shoot to root ratio of ${ }^{33} \mathrm{P}$ in the plants overexpressing OsPHT1;6 (Zhang F. et al., 2014) or OsPHT1;8 (Jia et al., 2011), indicating their role in phosphate allocation to the shoot. Nevertheless, we have to take into account that the observed changes in $\mathrm{Pi}$ distribution between root and shoot in transgenic plants may be caused by enhanced or defective uptake of Pi from nutrient solution.

\section{PHOSPHATE DISTRIBUTION WITHIN VEGETATIVE ORGANS}

Co-ordinated phosphate distribution between plant organs and tissues is crucial to maintain Pi-homeostasis, indispensable for continuous growth and development. Pi is allocated from the root to the shoot via xylem, but during leaf senescence or nutritional phosphorus deprivation it is mobilized from old leaves and transported via phloem to the sink organs (young leaves, growing roots, flowers, or seeds). After xylem or phloem unloading, $\mathrm{Pi}$ is subsequently transferred to the surrounding cells (Poirier and Bucher, 2002; Rausch and Bucher, 2002). Pi remobilization is a highly efficient process: in Arabidopsis up to $78 \%$ of phosphorus from senescing leaves is remobilized in this way (Nagarajan et al., 2011), and in Australian Hakea prostrata a minimum of $85 \%$ of Pi (Shane et al., 2014). In Pi release from organic compounds in senescing organs participate primary purple acid phosphatases (PAPs) and RNases, whose activity inside the cells and in the cell walls increases dramatically in these conditions. RNA may contain up to $60 \%$ of organic phosphorus in mature leaves, and its disruption by RNase causes the release of free nucleotides, which in consequence may become PAP substrates (Shane et al., 2014). Thus, although phosphorus may also be transported in the phloem sap in organic form (as hexosephosphate or nucleotides), $\mathrm{Pi}$ constitutes the main form of $\mathrm{P}$ in the phloem (Rausch and Bucher, 2002). In Pi distribution and recycling several rice and Arabidopsis PHT transporters are engaged.

Based on the expression pattern and mutants characteristics, it is presumed that $A$. thaliana phosphate transporter AtPHT1;5 plays a broad role in $\mathrm{Pi}$ redistribution between vegetative organs (Mudge et al., 2002; Nagarajan et al., 2011; Smith et al., 2011). Strong AtPHT1;5 promoter activity was detected in the cotyledons and hypocotyl of young Arabidopsis seedlings, suggesting a role of AtPHT1;5 in remobilization of Pi released from phytate (see next section) to developing organs (Mudge et al., 2002). In this process AtPHT1;5 may be supported by AtPHT1;9 expressed in the seedlings (Remy et al., 2012) and AtPHT1;1, whose promoter activity was detected in the peripheral layer of the endosperm (Mudge et al., 2002).

Mudge et al. (2002) found that after a few days following germination, AtPHT1;5 expression in the seedling drops, except cotyledons. Furthermore, in older plants AtPHT1;5-GUS labeling is restricted to the phloem cells of senescing leaves and flowers sepals. These findings gave credence to the notion that AtPHT1;5 is involved in the Pi redistribution process (Mudge et al., 2002). This conclusion is in agreement with later studies of AtPHT1;5 overexpressing Arabidopsis. These plants displayed premature senescence, reduced ${ }^{33} \mathrm{Pi}$ accumulation in older leaves and increased ${ }^{33} \mathrm{Pi}$ content in siliques as well as increased transcript levels of RNase and phosphatase in rosette leaves (older leaves). Moreover, mutation or overexpression of AtPHT1;5 led to altered $\mathrm{Pi}$ distribution between root and shoot; thereby under high $\mathrm{Pi}$ supply the mutant lines accumulate less $\mathrm{P}$ in roots, but more in shoots, when AtPHT1;5 overexpressors have higher root/shoot total $\mathrm{P}$ content in relation to the WT. Because AtPHT1;5 expression in shoot tissues is more intense when plants grow in high Pi supply, it is plausible that AtPHT1;5 function in these conditions involves re-translocation of phosphate from the shoot back to the root. However, under P-deficient stress the AtPHT1;5 promoter is active in the stele of the root, and in atpht 1;5 plants ${ }^{33} \mathrm{Pi}$ allocation to the shoot is up to $40 \%$ lower, indicating the role of AtPHT1;5 in xylem loading (Nagarajan et al., 2011). Generally, to sum up all the findings described above, we can conclude that, depending on $\mathrm{Pi}$ concentration in the environment and developmental cues, AtPHT1;5 may play a role in: Pi loading into the root xylem, Pi mobilization from senescing leaves and sepals, Pi re-translocation to the root, and Pi transport to the seedling and young growing organs (Mudge et al., 2002; Nagarajan et al., 2011; Smith et al., 2011). What is important, changes in AtPHT1;5 expression corresponded to differences in mRNA levels of PHO1 as well as to the P-starvation response modulators (miR399d and At) which highlights the significance of this transporter for $\mathrm{Pi}$ homeostasis (Smith et al., 2011). 
Other Arabidopsis transporters which may participate in $\mathrm{P}$ translocation in the shoot are AtPHT1;4 and AtPHT1;9. Apart from roots, among vegetative organs, the AtPHT1;9 transcript was found in the seedlings and senescing leaves, but not in the stem or young, adult or cauline leaves, so it may indicate that, similar to AtPHT1;5, AtPHT1;9 is involved in the Pi mobilization (Remy et al., 2012). AtPHT1;4 expression was detected in cotyledons, axillary buds, leaves, apical meristem and trichomes (Mudge et al., 2002; Misson et al., 2004). Furthermore, AtPHT1;4 mRNA level in the leaves of plants growing in Pidepleted and Pi-replete medium is similar to or even higher than the level of AtPHT1;5 transcript, but no specific role of AtPHT1;4 in leaves was determined (Nagarajan et al., 2011).

Promoter activity of four Arabidopsis PHT genes (AtPHT1;1, AtPHT1;3, AtPHT1;4, and AtPHT1;6) has been detected in the hydathodes of leaves and cotyledons (Mudge et al., 2002). It was described that guttation droplet composition of both organic (Pilot et al., 2004) and inorganic (Nagai et al., 2013) solutes is different from that of xylem sap, which implicates secretion or retrieval of nutrients from hydathodes. Thus, as was pointed out by Mudge et al. (2002), we may presume that expression of phosphate transporters in hydathodes is due to their contribution in $\mathrm{Pi}$ absorption from guttation fluid, which prevents $\mathrm{Pi}$ loss (Mudge et al., 2002). Based on expression in hydathodes, similar function might be attributed to other A. thaliana transporters, such as the $\mathrm{K}^{+}$channel AKT1 (Lagarde et al., 1996), sulfate transporters Sultr1;1 (Takahashi et al., 2000) and Sultr1;2 (Shibagaki et al., 2002), the nitrate transporter AtNRT2;1 (Nazoa et al., 2003) and the purine transporter AtPUP1 (Bürkle et al., 2003), while the GDU1 transporter is involved in glutamine excretion by hydathodes (Pilot et al., 2004). In fact, investigations of Nagai et al. (2013) clearly showed that potassium, nitrate and phosphate content in guttation fluid is lower, while chloride is higher, than concentrations of these ions in the xylem vessels close to hydathodes. Furthermore, Pi concentration in guttation droplets is almost zero, and an elegant experiment with tracing of ${ }^{32} \mathrm{P}$ by autoradiography demonstrated conclusively that ${ }^{32} \mathrm{Pi}$ can be taken up by hydathodes and redistributed to the whole plant within 1 day (Nagai et al., 2013).

It should also be noted that several AtPHO1 homologs are expressed in Arabidopsis leaves and stem: H1O across leaves, $H 1$ and $H 3$ in leaf vascular tissues, H4, H7, H8 and $H 10$ in hydathodes, $\mathrm{H} 8$ in trichomes, $\mathrm{H} 5, \mathrm{H} 7$, and $\mathrm{H} 10$ across the stem, and $H 1$ and $H 8$ in the vascular cylinder of the stem (Wang et al., 2004). Nevertheless, these expression results are not necessarily related to AtPHO1 involvement in Pi transport. The functions of major AtPHO1 proteins are unknown, and some of them play roles other than Pi translocation. For example, AtPHO1;H4 is localized in the nucleus and controls hypocotyl elongation in response to blue light, whereas AtPHO1;H10 is involved in stress responses (cold, salt, pathogens, etc.; Baker et al., 2015).

It was proposed that in the root $\mathrm{Pi}$ redistribution may be accomplished by AtPHT1;8 and AtPHT1;9, despite their functioning in xylem loading. AtPht1;8 and AtPht1;9 transcripts are detected in metaphloem, protophloem and phloem companion cells but only in the meristematic region. AtPht $1 ; 8$ and AtPht $; 99$ presence in this root zone is presumably correlated with controlling $\mathrm{Pi}$ redistribution between shoot and root by phloem sap, and thus probably the phloem unloading process (Lapis-Gaza et al., 2014). Alternatively, if AtPht1;8 and AtPht1;9 activity will be detected in the upper part of the root phloem, we will be able to assign them a function similar to AtNRT1;9 nitrate transporter. This protein expressed in root companion cells is responsible for phloem loading and therefore the downward transport of nitrate in roots, to regulate $\mathrm{NO}_{3}{ }^{-}$distribution in response to environmental changes (Wang and Tsay, 2011).

In rice leaves expression of OsPHT1;1 (Seo et al., 2008; Sun et al., 2012), OsPHT1;2 (Ai et al., 2009), OsPHT1;4 (Ye et al., 2015), OsPHT1;6 (Ai et al., 2009), OsPHT1;8 (Jia et al., 2011; Li et al., 2015), OsPHT1;9, OsPHT1;10 (Wang X.F. et al., 2014) and OsPHT1;13 (Liu et al., 2011) was detected. The crosssection of the leaf blades of transgenic plants expressing the GUS gene under the control of OsPHT1 promoters, indicating that promoters of almost all genes (except OsPHT1;4 and OsPHT1;13, for which data about tissue-specific expression in the leaves are not available) are preferentially active in mesophyll, phloem and xylem, whereas their activity in epidermal cells is low (Ai et al., 2009; Jia et al., 2011; Sun et al., 2012; Wang X.F. et al., 2014). This expression pattern may be related to $\mathrm{Pi}$ mobility. It was shown that when other ions such as $\mathrm{Na}^{+}, \mathrm{K}^{+}, \mathrm{Ca}^{2+}, \mathrm{NO}_{3}{ }^{-}$, and $\mathrm{Cl}^{-}$accumulate to the greatest extent in epidermal tissue, $\mathrm{Pi}$ concentrates in mesophyll cells, which probably favors quick $\mathrm{Pi}$ transfer to the phloem system during phosphate deprivation or leaf senescence (Nagai et al., 2013).

It was suggested that in $\mathrm{Pi}$ translocation from older leaves to sink organs OsPHT1;4 (Ye et al., 2015), OsPHT1;6 (Zhang F. et al., 2014) and OsPHT1;8 (Li et al., 2015) participate, but we cannot exclude the direct involvement of other rice Pi transporters, because of limited information. OsPHTT1;4 is intensively expressed in the flag leaf but also in roots, culm, ligule, and generative organs. Its expression increases under limiting Pi conditions and changes during rice development, reaching a peak in flag leaves after pollination. Flag leaves are the key source of Pi for developing seeds, and OsPHT1;4 overexpressing plants accumulate $26 \%$ more $\mathrm{Pi}$ in brown rice, so OsPHT1;4 may be involved in $\mathrm{Pi}$ remobilization from flag leaves and its translocation to the panicle. However, it is worth noting that OsPHT1;4 expression after pollination is also enhanced in the roots. Thus, higher concentration of $\mathrm{Pi}$ in the transgenic rice grains may be a sum of increasing Pi uptake, translocation and remobilization, especially considering that in field conditions this rice accumulates about two times more $\mathrm{Pi}$ in the straw, while RNAi lines are characterized by fewer tillers and roots (Ye et al., 2015). Detailed investigation of OsPHT1;6 and OsPHT1;8 revealed their roles in $\mathrm{Pi}$ remobilization from senescing to young leaves and rice grains. OsPTH1;6 overexpression is correlated with higher total $\mathrm{P}$ concentration in the shoot tissue and increasing in shoot biomass. Plants have also significantly higher $\mathrm{P}$ content in young leaves, compared to old leaves, that in WT plants (Zhang F. et al., 2014). Analogically, selective knockdown of OsPHT1;8 only in the rice shoot caused increase in Pi and total $\mathrm{P}$ concentration in old leaves by $50-250 \%$, altered expression of phosphate starvation induced genes in young and old leaves, and reduced total $\mathrm{P}$ content in both embryo and endosperm ( $\mathrm{Li}$ 
et al., 2015). In contrast, in P-replete conditions, overexpression of OsPHT1,1 resulted in increased Pi concentration in xylem sap and young leaves, but not in lower Pi concentration in old leaves. This clearly indicates that these changes are caused by enhanced Pi uptake and/or allocation to aerial plant organs, but not by increased remobilization of phosphate from senescent leaf blades (Sun et al., 2012).

\section{PHOSPHATE MOVEMENT IN REPRODUCTIVE TISSUES}

During flowering and seed formation, transport of Pi from source organs to reproductive organs occurs. It is well-documented that $\mathrm{Pi}$ availability in the soil and its concentration in plant tissues have a strong impact on plant reproductive success (Lau and Stephenson, 1994; Zhang Z. et al., 2014). In the developing seeds, $\mathrm{Pi}$ and inositol are used for synthesis of phytic acid (myo-inositolhexakisphosphate). Phytic acid creates salts with potassium, calcium, magnesium and iron, commonly named phytate, which is the main form of phosphate storage in the endosperm and embryo. During germination, due to activity of phytases, phytate is broken down, and phosphate, inositol and cations are released and are using for seedling growth and development (Azeke et al., 2011; Li et al., 2015). Moreover, Pi is not only transported to female organs and, after pollination, to the newly formed embryo, but is also stored in the pollen. It was shown that pollen grains from plants growing in $\mathrm{Pi}$-rich soil have a higher $\mathrm{Pi}$ concentration and pollen grain volume. Because $\mathrm{P}$ stored in the pollen is used for example for phospholipid synthesis, which occurs rapidly during pollen tube growth, pollen from plants growing in high $\mathrm{Pi}$ concentration sired more seeds when competing for the same ovule with pollen from Pi-stressed plants (Lau and Stephenson, 1994).

Relatively little is known about phosphate transport into and out of Arabidopsis flowers and seeds. Although, all PHO1 homologs, except $\mathrm{PHO} 1 ; \mathrm{H} 2$, were reported to be expressed in some parts of flowers or germinating pollen grains (in the petals, sepals or filament vasculature, receptacle, stigma apex, anther connectives, pollen grains or pollen tube), their role in flower development is enigmatic (Wang et al., 2004). In flower buds, among AtPHT1 representatives, only activity of the AtPHT1;5 promoter was detected (Mudge et al., 2002). However, weak AtPHT1;9 expression in flowers was demonstrated by RT-PCR analysis, but unfortunately the authors did not specify in which flower part or in which flower developmental stage (Remy et al., 2012). During development of gametophytes Pi is transported to the growing ovule and microspores. Although no AtPHT1 gene expression in Arabidopsis pistils was detected, in mature pollen expression of AtPHT1;6 and AtPHT1;7 was reported. AtPHT1;6 promoter activity was also noted in anthers, especially in the tapetum (Mudge et al., 2002), the cells supplying nutrients to developing microspores as well as being a source of lipids composing the pollen coat (Furness and Rudall, 2001). For Pi transport to Arabidopsis seeds, AtPHT1;9 (Remy et al., 2012) and probably AtPHT1;5 (Nagarajan et al., 2011) are responsible. Quantitative trait locus (QTL) analysis identified AtPHT1;9 as a marker of Pi concentration in the seeds, although the AtPHT1;9 transcript level in the Arabidopsis siliques was low and no germination defects were detected in the atpht1;9 mutant (Remy et al., 2012). Overexpression of AtPHT1;5 leads to twofold higher $\mathrm{Pi}$ concentration in the siliques, but this effect may arise from enhanced Pi export from old leaves, not from the direct influence of AtPHT1;5 on Pi transfer to the seeds (Nagarajan et al., 2011). Finally, in the fading flowers (in the senescing anther filaments and sepals respectively) AtPHT1;4 and AtPHT1;5 expression occurs. AtPHT1;4 is also specifically expressed in the silique abscising zone. This probably reflects the ability of $A$. thaliana to re-mobilize Pi out of aging flowers and fruits to support growth of other plant organs (Karthikeyan et al., 2002; Mudge et al., 2002).

More investigations have been focused on OsPHT1 transporters in rice grains. Rice is the staple food for around $50 \%$ of the world's population (Zhang F. et al., 2014), so overexpression or down-regulation of particular OsPHT1 in this crop may have a practical, measurable impact. Based on high expression in the embryo, three genes have emerged as important for development of rice seeds - OsPHT1;1, OsPHT1;4, and OsPHT1;8 (Zhang et al., 2015) - and involvement of two of them - OsPHT1;4 (Zhang et al., 2015) and OsPHT1;8 (Jia et al., 2011; Li et al., 2015) - in this process was confirmed. OsPHT1;4 expression in the embryo was around 10 times higher than in the endosperm or panicle axis. Knockdown and knockout of OsPHT1;4 caused a $21-24 \%$ reduction of the total $\mathrm{P}$ amount in the embryo, but not in the endosperm, a $22-32 \%$ decrease in phytic acid concentration in the seeds as well as downregulation of genes involved in phytic acid synthesis and lower embryo size. In contrast, OsPHT1;4 overexpressing lines have higher total $\mathrm{P}$ content in the embryo and endosperm, higher phytic acid concentration and higher expression of phytic acid synthesis enzymes than wild type. But, what is more important, altered expression of OsPHT1;4 affects panicle performance, grain filling and seed germination of transgenic $O$. sativa. The panicles of knockout and RNAi lines are less robust and have 50-58\% lower seed-setting rates than WT. Grain yield per plant and 1000-grain weight in knockout and knockdown rice lines also decreased. In consequence of mutation or downregulation of OsPHT1;4, germination of seeds is retarded: emergence of the radical and plumule occurs later after imbibition, and the shoot and root of young seedling are shorter than in WT plants. In contrast, OsPHT1;4 overexpressors have higher 1000-grain weight and percentage germination rate (Zhang et al., 2015). Similarly, downregulation or mutation of OsPHT1;8 results in 30\% higher total $\mathrm{P}$ content in the panicle axis, 30\% lower total $\mathrm{P}$ content in unfilled grain hulls and a decreased seed-setting rate (Jia et al., 2011), while selective attenuation of OsPHT1;8 in seed endosperm leads to a $40-50 \%$ reduction of total $\mathrm{P}$ content in the embryo but not in the endosperm, compared with WT (Li et al., 2015). This implies OsPHT1;8 participation in Pi transfer from the panicle axis to the seeds (Jia et al., 2011) and from the endosperm to the embryo (Li et al., 2015). Although some similarities between OsPHT1;4 and OsPHT1;8 functioning exist, we can speculate that they play a different role in rice grain development. In ospht1;4 and OsPHT1;4 RNAi plants transcript levels of OsPHT1;1 and OsPHT1;8 are significantly increased, but 
they do not compensate disruption or suppression of OsPHT1;4 (Zhang et al., 2015). Moreover, the microarray expression profile of all 26 PHT rice genes in 27 tissues covering the plant lifecycle in three rice cultivars did not show higher expression of OsPHT1;1, OsPHT1;4, or OsPHT1;8 in germinating rice seeds but $72 \mathrm{~h}$ of the imbibition stage specific and high expression of another gene, OsPHT1;12, were detected (Liu et al., 2011). OsPHT1;12 together with OsPHT1;7, are also strongly expressed in the anthers (Gu et al., 2016).

\section{INTRACELLULAR Pi TRANSPORTERS}

\section{Pi Transport Across the Vacuole Membrane}

The translocation of $\mathrm{Pi}$ to subcellular organelles is crucial for metabolic regulation and homeostasis of $\mathrm{Pi}$ in the plant cell. The vacuole plays a central role in $\mathrm{Pi}$ sequestration, and it is the major Pi storage compartment (Raghothama, 1999). Under $\mathrm{Pi}$-sufficient conditions, to prevent toxicity of cytoplasm, $\mathrm{Pi}$ excess is stored in the vacuole, whereas under $\mathrm{Pi}$ deficiency inorganic phosphate is exported from the vacuole to the cytosol (Shane et al., 2004). However, very little is known, compared to other organelles, about protein exchangers that are required for movement of $\mathrm{Pi}$ in and out of the vacuole (Bucher and Fabiańska, 2016). Two independent research groups, using different technics for the functional characterization of vacuolar Pi transporters, made an important discovery. Liu et al. (2015) using patch-clamping methods, identified in $A$. thaliana an ortholog of OsSPX-MFS1, namely VPT1, that operates as an influx transporter in the tonoplast (Figure 3). A number of genetic studies on the $v p t 1$ and electrophysiological approaches suggested that VPT1 might act as an anion channel in the tonoplast (Liu et al., 2015). The VPT1 was also named PHT5;1 in the article by Liu T. et al. (2016). They determined using ${ }^{31} \mathrm{P}$ - MRS (magnetic resonance spectroscopy) the translocation of Pi across the tonoplast in wild type plants (Liu T. et al., 2016). The knock-out mutants of PHT5;1 exhibited toxic concentration of $\mathrm{Pi}$ in cytoplasm. Furthermore, the analyses of Arabidopsis mutants and overexpression lines suggested that two other proteins - PHT5;2 and PHT5;3- also participated in vacuolar Pi sequestration (Liu T. et al., 2016). Previously, vacuolar transporters have been studied only in yeast and rice. In O. sativa three proteins belonging to the SPX-MFS family: OsSPX-MFS1, OsSPX-MFS2, OsSPX-MFS3, have been identified as involved in Pi transport across the vacuolar membrane (Wang et al., 2015). The SPX-MFS (Major Facilitator Superfamily) proteins contain 10-11 transmembrane domains and function as transport carriers (uniporters, symporters, or antiporters) for different substrates, i.e., ions and organic compounds (Secco et al., 2012). It is suggested that these proteins are key players in $\mathrm{Pi}$ signaling, transport and remobilization in leaves (Lin et al., 2010). Overexpression of OsSPX-MFS1 in yeast cells and complementation of pht5;1 with OsSPX-MFS1 indicated that OsSPX-MFX1 acts as a Pi channel (Liu F. et al., 2016). Whereas OsPSX-MFS3 is proposed as a vacuolar efflux $\mathrm{Pi}: \mathrm{H}^{+}$symporter (Wang et al., 2015; Figure 3).

\section{Pi Transport Across the Mitochondrial Membrane}

The mitochondrial phosphate transporters (MPTs) are responsible for transporting $\mathrm{Pi}$ into the mitochondrial matrix, where $\mathrm{Pi}$ is utilized for oxidative phosphorylation of ADP to ATP by ATP synthase (Monné et al., 2015). MPTs act as $\mathrm{Pi}: \mathrm{H}^{+}$ symporters or $\mathrm{Pi} / \mathrm{OH}^{-}$antiporters between mitochondria and the cytosol (Stappen and Krämer, 1994). In A. thaliana phosphate transport across the mitochondrial membrane is mediated by PHT3 proteins (Figure 1) belonging to the mitochondrial carrier family (MCF), together with ADP/ATP carriers (Haferkamp and Schmitz-Esser, 2012; Lorenz et al., 2015). PHT3s in A. thaliana are encoded by three genes, named AtPHT3;1, AtPHT3;2, and AtPHT3;3 (Poirier and Bucher, 2002). Most are expressed in multiple cell layers in stems, leaves and flowers (Zhu et al., 2012). It was reported that AtPHT3;1 and AtPHT3;2 are strongly upregulated by salt stress, and overexpression of these genes leads to increased sensitivity to salt stress in Arabidopsis seedlings (Zhu et al., 2012).

Some studies have reported that cDNA encoding MPT proteins was isolated from other plants, i.e., soybean, maize, and Lotus japonicas (Takabatake et al., 1999; Nakamori et al., 2002). So far, only one report, by Liu et al. (2011) has described mitochondrial PHT family genes in the rice genome. Using the microarray method, the expression of all 26 genes of the PHT family was characterized. Moreover, the phylogenetic tree of PHT was generated, based on full-length amino acid sequences from Arabidopsis and O. sativa. One of the four clusters, namely cluster III, contains nine members: three from Arabidopsis (AtPHT3;1 AtPHT3;3) and six from rice (OsPT15, 16, 17, 18, 19, 20; Liu et al., 2011). However, the same phylogenetic grouping does not mean the same subcellular localization, because none of these six proteins (OsPT15-20) were found in mitochondria, like the mentioned PHT3 members from Arabidopsis. OsPT15, 17, 18,19 are located in peroxisomes, OsPT16 on the endoplasmic reticulum and OsPT17 on the plasma membrane (Liu et al., 2011).

\section{Pi Transport Across the Golgi System}

The Golgi apparatus plays a fundamental role in intracellular trafficking, protein glycosylation, and non-cellulosic polysaccharide synthesis in plant cells. The wall polysaccharides are synthesized from nucleotide sugar substrates, which are transported into the Golgi by nucleotide sugar transporters (NSTs) and here nucleoside diphosphates are hydrolyzed to nucleoside monophosphates and Pi (Driouich et al., 2012). It has been shown that a specific transporter exports Pi out of the Golgi. Subcellular localization using GFP fusion confirmed that only one member of the PHT4 family of intracellular Pi transporters is targeted to the Golgi apparatus in Arabidopsis (Figure 3). AtPHT4;6 mediates the transport of Pi from the Golgi toward the cytosol (Guo et al., 2008a). The role of AtPHT4;6 as a $\mathrm{Pi}$ exporting protein was supported by identification and characterization of the atpht4;6 mutant, which is hypersensitive to salt stress, especially in plants growing under $\mathrm{Pi}$ starvation (Cubero et al., 2009). Disruption of the AtPHT4;6 gene results also in strong growth inhibition and alteration of cell wall 

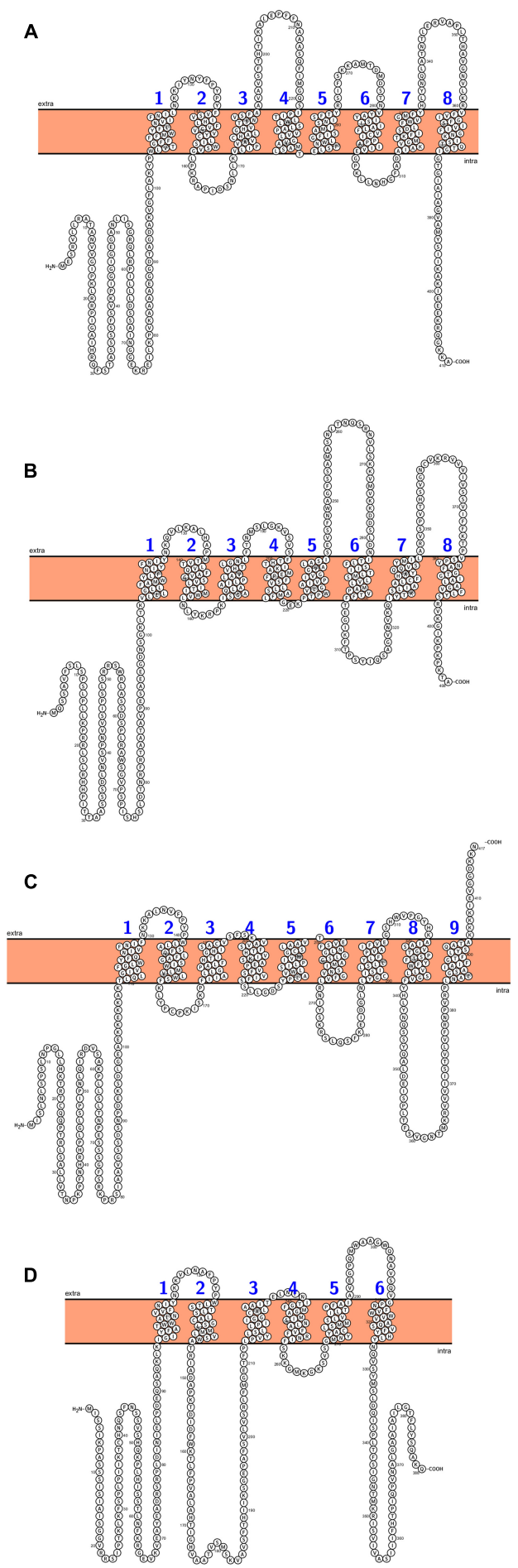

FIGURE 4 | Arabidopsis chloroplast's phosphate translocators predicted topology: (A) TPT (triose-phosphate/phosphate translocator), (B) PPT1 (phosphoenolpyruvate/phosphate translocator), (C) XPT (xylulose-5-phosphate/phosphate translocator), (D) GPT2 (glucose-6-phosphate/phosphate translocator). All figures were performed in Protter (Protter: interactive protein feature visualization and integration with experimental proteomic data. Omasits et al., 2014), protein sequences come from UniProt database. composition with reduced levels of rhamnose and mannose and increased levels of fructose and arabinose (Hassler et al., 2012). Two homologs of AtPHT4;6 have been found in the rice secretory system (Guo et al., 2008b). However, our knowledge on phosphate transport across endomembranes in rice is still limited.

\section{Phosphate Transport in Plastids}

In plastids three classes of $\mathrm{Pi}$ transporters have been characterized: PHT2, PHT4 and Pi translocators (Figures 1, 3, and 4; Poirier and Bucher, 2002; Rausch and Bucher, 2002). AtPHT2;1 is currently the only transporter of the PHT2 family identified in Arabidopsis (Figure 1). The cDNA encodes a 12-transmembrane protein with high homology to fungal and mammalian $\mathrm{Na}^{+} / \mathrm{Pi}$ transporters (Daram et al., 1999). The AtPHT2;1 gene is predominantly expressed in green tissue and AtPHT2-GFP fusion protein indicates that AtPHT2;1 is located in the chloroplast inner envelope membrane (Versaw and Harrison, 2002). Mutant atpht2;1 reveals reduced transport into the chloroplast and contains 20 times less Pi compared to the wild type (Versaw and Harrison, 2002). Similar to Arabidopsis AtPHT2;1 the rice ortholog OsPHT2;1 is expressed mainly in leaves and is induced by phosphate deficiency and light (Shi et al., 2013).

The functional analysis of the PHT4 family (Figure 1) and subcellular localization in Arabidopsis of all 5 members AtPHT4;1 - AtPHT4;5 were described in detail by Guo et al. (2008a). These proteins share similarities with mammalian SLC17/type I transporters that are involved in the transport of Pi and chloride (Reimer and Edwards, 2004). AtPHT4;1, AtPHT4;2, AtPHT4;4, and AtPHT4;5 have been visualized in plastids using protein GFP fusion. More advanced analyses of purified plastids and GUS activity revealed that AtPHT4;1 and AtPHT4;4 are localized in leaf chloroplasts, AtPHT4;2 in root plastids, and AtPHT4;3 and AtPHT4;5 in shoot plastids (Guo et al., 2008a). The AtPHT4;1, also known as the anion transporter ANTR1, has been characterized as a $\mathrm{H}^{+}$-dependent high affinity Pi transporter when expressed in yeast (Guo et al., 2008b) and $\mathrm{Na}^{+}$-dependent transporter using Escherichia coli system (Pavón et al., 2008). It was also documented that AtPHT4;2 (Irigoyen et al., 2011) and AtPHT4;4 (Finazzi et al., 2015) mediate $\mathrm{H}^{+}$ or $\mathrm{Na}^{+}$dependent Pi symport. Mutation of the AtPHT4;1 gene (atpht4;1) leads to a dwarf phenotype with smaller leaf rosette and reduced biomass compared to WT plants (Karlsson et al., 2015). Due to lower level of Pi in pht4;1 mutant, the activity of ATP-synthase is inhibited and this in turn, leads to decrease level of ATP and reduction in accumulation of soluble sugars, which could limit plant growth (Karlsson et al., 2015). Moreover, mutant pht4;1 was more susceptible to infection with virulent bacterium Pseudomonas syringae, but salicylic acid induced pathogen resistance in this mutant (Wang et al., 2011). Therefore, it was proposed that AtPHT4; 1 is required to control the immune response to pathogen infection and its expression is dependent on circadian clock protein CCA1 (Wang et al., 2011; Wang G. et al., 2014). Furthermore, Miyaji and co-workers speculated that AtPHT4;1 may transport ascorbate into the lumen to overcome photoinhibition caused by strong light (Miyaji et al., 2015). 
However, evaluation of ascorbate content at high light conditions conducted independently by Karlsson et al. (2015) did not reveal any differences between WT and the atpht4.1 mutant line. Thus, the hypothesis that AtPHT4;1 transports ascorbate into the lumen has not been confirmed. According to obtained data from proteoliposome assay, other protein, namely, AtPHT4;4 might transport ascorbate (Miyaji et al., 2015). Atpht4;4 mutant exhibited reduced level of ascorbate (about 30\%) in leaves and defect in the xanthophyll cycle. AtPHT4;4 is expressed in chloroplast and its level increased under light exposure (Miyaji et al., 2015). It has been documented that AtPHT4;2 contributes to $\mathrm{Pi}$ transport in root plastids and expression of the AtPHT4;2 gene is restricted to roots and floral tissue (Irigoyen et al., 2011). The atpht4;2 mutant surprisingly exhibited a larger rosette size, caused by increased cell proliferation in the leaf, as well as reduced starch biosynthesis in shoots as an inhibitory effect of Pi excess on ADP-glucose pyrophosphorylase, the key enzyme in starch synthesis (Irigoyen et al., 2011). Based on TIGR rice genome database seven protein sequences of PHT4 was found in rice and they share about $70-80 \%$ similarity to Arabidopsis orthologs (PHT4;1, $4 ; 2,4 ; 3 ; 4 ; 4,4 ; 5$ and two homologs of PHT4;6; Guo et al., 2008b).

Several transporters localized in the inner envelope membrane connect the metabolism processes between chloroplasts, mitochondria, and surrounding cytosol. There are 4 plastid translocators: triose-phosphate/phosphate translocator (TPT), exporting the photosynthetically fixed carbon in a form of triosephosphates, the phosphoenolpyruvate/phosphate translocator (PPT) that delivers the phosphoenolpyruvate from the cytosol, the pentose xylulose-5-phosphate/phosphate translocator (XPT), and the glucose-6-phosphate/phosphate translocator which mediates import of carbon skeletons to non-photosynthetic plastids (Weber, 2004; Flügge et al., 2011). Phylogenetic analyses showed that plastid phosphate translocators originated from an red algal ancestor and their homologs in other plants (cauliflower, tobacco, pea, spinach, potato, maize) were founded. (Kammerer et al., 1998; Weber et al., 2006; Weber and Linka, 2011). The Arabidopsis genome contains a single copy for TPT and XPT genes, and two genes encoding PPT and GPT, respectively (Figure 4). TPT genes are expressed primarily in photosynthetic tissue. GPT is expressed only in nonphotosynthetic plastids, whereas $P P T$ are expressed in both photosynthetic and non- photosynthetic tissues (Knappe et al., 2003). The cue1 (chlorophyll a/b binding protein CAB gene underexpressed 1) mutant is defective in PPT translocator and was first time described by Li et al. (1995). Mutation at this gene resulted in reticulate leaf phenotype and reduction of chlorophyll and carotenoids content (Li et al., 1995; Streatfield

\section{REFERENCES}

Ai, P. H., Sun, S. B., Zhao, J. N., Fan, X. R., Xin, W. J., Guo, Q., et al. (2009). Two rice phosphate transporters, OsPht $1 ; 2$ and OsPht1;6, have different functions and kinetic properties in uptake and translocation. Plant J. 57, 798-809. doi: 10.1111/j.1365-313X.2008.03726.x et al., 1999). Mutants that lack the activity of TPT (tpt1) show similar phenotype to that of WT plants without any changes in leaves size or in fresh weight (Schneider et al., 2002). Disruption of GPT1 resulted in several defects, especially during pollen development (pollen with reduced storage lipids) and lower concentration of starch in leaves (Niewiadomski et al., 2005). Loss of GPT2 has no effect on plant growth and development, whereas mutation of GPT1 is lethal (Niewiadomski et al., 2005). The genes encoding the putative plastid translocators in rice were identified and they were named after Arabidopsis homologs. Thus, two functional rice TPT genes (OsTPT1,OsTPT2), four GPT (OsGPT1, OsGPT2-1, OsGPT2-2, OsGPT2-3), and four PPT genes (OsPPT1, OsPPT2, OsPPT3, OsPPT4) were found in rice genome and their expression patterns in various organs were examined by Toyota et al. (2006). The OsTPT and OsPPT were expressed predominantly in leaves, whereas the expression of the OsGPT1, OsGPT2-1 and OsGPT 2-2 was much higher in seed compared to the photosynthetic tissues. None of rice xylolose-5phosphate genes and proteins (XPT) have been characterized so far (Toyota et al., 2006).

\section{Summary}

In summary, many transporter proteins and their respective genes have been identified and characterized, but the physiological role of $\mathrm{Pi}$ transporters in response to $\mathrm{Pi}$ starvation is still very limited. Understanding of the molecular mechanism involved in the regulation of phosphate transporters is very important, due to the constantly lower availability of phosphorus reserves in nature, and will facilitate the development of more efficient Pi-utilizing plants.

\section{AUTHOR CONTRIBUTIONS}

All authors listed, have made substantial, direct and intellectual contribution to the work, and approved it for publication.

\section{ACKNOWLEDGMENTS}

We are grateful to Professor Grażyna Kłobus (Department of Plant Molecular Physiology, Institute of Experimental Biology, University of Wrocław) for critical reading of the manuscript.

\section{SUPPLEMENTARY MATERIAL}

The Supplementary Material for this article can be found online at: http://journal.frontiersin.org/article/10.3389/fpls.2016.01198

Amtmann, A., Hammond, J. P., Armengaud, P., and White, P. (2006). Nutrient sensing and signalling in plants: potassium and phosphorus. Adv. Bot. Res. 43, 209-257. doi: 10.1016/S0065-2296(05) 43005-0

Arpat, A. B., Magliano, P., Wege, S., Rouached, H., Stefanovic, A., and Poirier, Y. (2012). Functional expression of PHO1 to the Golgi and trans-Golgi network 
and its role in export of inorganic phosphate. Plant J. 71, 479-491. doi: 10.1111/j.1365-313X.2012.05004.x

Ayadi, A., David, P., Arrighi, J. F., Chiarenza, S., Thibaud, M. C., Nussaume, L., et al. (2015). Reducing the genetic redundancy of Arabidopsis PHOSPHATE TRANSPORTER1 transporters to study phosphate uptake and signaling. Plant Physiol. 167, 1511-1526. doi: 10.1104/pp.114.252338

Azeke, M. A., Egielewa, S. J., Eigbogbo, M. U., and Ihimire, I. G. (2011). Effect of germination on the phytase activity, phytate and total phosphorus contents of rice (Oryza sativa), maize (Zea mays), millet (Panicum miliaceum), sorghum (Sorghum bicolor) and wheat (Triticum aestivum). J. Food Sci. Technol. 48, 724-729. doi: 10.1007/s13197-010-0186-y

Aziz, T., Finnegan, P. M., Lambers, H., and Jost, R. (2014). Organ-specific phosphorus- allocation patterns and transcript profiles linked to phosphorus efficiency in two contrasting wheat genotypes. Plant Cell Environ. 37, 943-960. doi: $10.1111 /$ pce. 12210

Baker, A., Ceasar, S. A., Palmer, A. J., Paterson, J. B., Qi, W., Muench, S. P., et al. (2015). Replace, reuse, recycle: improving the sustainable use of phosphorus by plants. J. Exp. Bot. 66, 3523-3540. doi: 10.1093/jxb/erv210

Balzergue, C., Chabaud, M., Barker, D. G., Bécard, G., and Rochange, S. F. (2013). High phosphate reduces host ability to develop arbuscular mycorrhizal symbiosis without affecting root calcium spiking responses to the fungus. Front. Plant Sci. 4:426. doi: 10.3389/fpls.2013.00426

Breuillin, F., Schramm, J., Hajirezaei, M., Ahkami, A., Favre, P., Druege, U., et al. (2010). Phosphate systemically inhibits development of arbuscular mycorrhiza in Petunia hybrida and represses genes involved in mycorrhizal functioning. Plant J. 64, 1002-1017. doi: 10.1111/j.1365-313X.2010. 04385.x

Bucher, M. (2007). Functional biology of plant phosphate uptake at root, and mycorrhiza interfaces. New Phytol. 173, 11-26. doi: 10.1111/j.14698137.2006.01935.x

Bucher, M., and Fabiańska, I. (2016). Long-sought vacuolar phosphate transporters identified. Trends Plant Sci. 21, 463-466. doi: 10.1111/j.1469-8137.2006.01935.x

Bürkle, L., Cedzich, A., Döpke, C., Stransky, H., Okumoto, S., Gillisen, B., et al. (2003). Transport of cytokinins mediated by purine transporters of the PUP family expressed in phloem, hydathodes, and pollen of Arabidopsis. Plant J. 34, 13-26. doi: 10.1046/j.1365-313X.2003.01700.x

Ceasar, S. A., Hodge, A., Baker, A., and Baldwin, S. A. (2014). Phosphate concentration and arbuscular mycorrhizal colonisation influence the growth, yield and expression of twelve PHT1 family phosphate transporters in foxtail millet (Setaria italica). PLOS ONE 9:e108459. doi: 10.1371/journal.pone.0108459

Chen, A., Chen, X., Wang, H., Liao, D., Gu, M., Qu, H., et al. (2014). Genomewide investigation and expression analysis suggest diverse roles and genetic redundancy of Pht1 family genes in response to Pi deficiency in tomato. BMC Plant Biol. 11:61. doi: 10.1186/1471-2229-14-61

Chen, A., Hu, J., Sun, S., and Xu, G. (2007). Conservation and divergence of both phosphate- and mycorrhiza-regulated physiological responses and expression patterns of phosphate transporters in solanaceous species. New Phytol. 173, 817-831. doi: 10.1111/j.1469-8137.2006.01962.x

Chiba, Y., Shimizu, T., Miyakawa, S., Kanno, Y., Koshiba, T., Kamiya, Y., et al. (2015). Identification of Arabidopsis thaliana NRT1/PTR FAMILY (NPF) proteins capable of transporting plant hormones. J. Plant Res. 128, 679-686. doi: 10.1007/s10265-015-0710-2

Chiou, T. J., and Lin, S. I. (2011). Signaling network in sensing phosphate availability in plants. Annu. Rev. Plant Physiol. 62, 185-206. doi: 10.1146/annurev-arplant-042110-103849

Chiou, T. J., Liu, H., and Harrison, M. J. (2001). The spatial expression patterns of a phosphate transporter (MtPT1) from Medicago truncatula indicate a role in phosphate transport at the root/soil interface. Plant J. 25, 1-15. doi: 10.1046/j.1365-313x.2001.00963.x

Christophersen, H. M., Smith, F. A., and Smith, S. E. (2009). Arbuscular mycorrhizal colonization reduces arsenate uptake in barley via downregulation of transporters in the direct epidermal phosphate uptake pathway. New Phytol. 184, 962-974. doi: 10.1111/j.1469-8137.2009.03009.x

Cubero, B., Nakagawa, Y., Jiang, X. Y., Miura, K. J., Li, F., Raghothama, K. G., et al. (2009). The phosphate transporter PHT4;6 is a determinant of salt tolerance that is localized to the golgi apparatus of Arabidopsis. Mol. Plant 2, 535-552. doi: $10.1093 / \mathrm{mp} / \mathrm{ssp} 013$
Daram, P., Brunner, S., Persson, B. L., Amrhein, N., and Bucher, M. (1998). Functional analysis and cell- specific expression of a phosphate transporter from tomato. Planta 206, 225-233. doi: 10.1007/s004250050394

Daram, P., Brunner, S., Rausch, C., Steiner, C., Amrhein, N., and Bucher, M. (1999). Pht2;1 encodes a low-affinity phosphate transporter from Arabidopsis. Plant Cell 11, 2153-2166. doi: 10.2307/3871016

Davies, T. G. E., Ying, J., Xu, Q., Li, Z. S., Li, J., and Gordon-Weeks, R. (2002). Expression analysis of putative high-affinity phosphate transporters in Chinese winter wheats. Plant Cell Environ. 25, 1325-1339. doi: 10.1046/j.13653040.2002.00913.x

DiTusa, F. S., Fontenot, E. B., Wallace, R. W., Silvers, M. A., Steele, T. M., Elnagar, A. H., et al. (2016). A member of the Phosphate transporter 1 (Pht1) family from the arsenic-hyperaccumulating fern Pteris vittata is a high-affinity arsenate transporter. New Phytol. 209, 762-772. doi: 10.1111/nph.13472

Driouich, A., Follet-Gueye, M. L., Bernard, S., Kousar, S., Chevalier, L., VicréGibouin, M., et al. (2012). Golgi-mediated synthesis and secretion of matrix polysaccharides of the primary cell wall of higher plants. Front. Plant Sci. 3:79. doi: $10.3389 /$ fpls.2012.00079

Duan, J., Tian, H., Drijber, R. A., and Gao, Y. (2015). Systemic and local regulation of phosphate and nitrogen transporter genes by arbuscular mycorrhizal fungi in roots of winter wheat (Triticum aestivum L.). Plant Physiol. Biochem. 96, 199-208. doi: 10.1016/j.plaphy.2015.08.006

Fan, C., Wang, X., Hu, R., Wang, Y., Xiao, C., Jiang, Y., et al. (2013). The pattern of Phosphate transporter 1 genes evolutionary divergence in Glycine max L. BMC Plant Biol. 13:48. doi: 10.1186/1471-2229-13-48

Finazzi, G., Petroutsos, D., Tomizioli, M., Flori, S., Sautron, E., Villanova, V., et al. (2015). Ions channels/transporters and chloroplast regulation. Cell Calcium 58, 86-97. doi: 10.1016/j

Flügge, U., Häusler, R. E., Ludewig, F., and Gierth, M. (2011). The role of transporters in supplying energy to plant plastids. J. Exp. Bot. 62, 2381-2392. doi: $10.1093 /$ jxb/erq361

Furness, A., and Rudall, P. J. (2001). Pollen and anther characters in monocot systematics. Grana 40, 1-2. doi: 10.1080/00173130152591840

Glassop, D., Godwin, R. M., Smith, S. E., and Smith, F. W. (2007). Rice phosphate transporters associated with phosphate uptake in rice roots colonised with arbuscular mycorrhizal fungi. Can. J. Bot. 85, 644-651. doi: 10.1139/B07-070

Glassop, D., Smith, S. E., and Smith, F. W. (2005). Cereal phosphate transporters associated with the mycorrhizal pathway of phosphate uptake into roots. Planta 222, 688-698. doi: 10.1007/s00425-005-0015-0

Gojon, A., Krouk, G., Perrine-Walker, F., and Laugier, E. (2011). Nitrate transceptor(s) in plants. J. Exp. Bot. 62, 2299-2308. doi: 10.1093/jxb/erq419

Gordon-Weeks, R., Tong, Y., Davies, T. G. E., and Leggewie, G. (2003). Restricted spatial expression of a high-affinity phosphate transporter in potato roots. J. Cell Sci. 116, 3135-3144. doi: 10.1242/jcs.00615

Grace, E. J., Cotsaftis, O., Tester, M., Smith, F. A., and Smith, S. E. (2009). Arbuscular mycorrhizal inhibition of growth in barley cannot be attributed to extent of colonization, fungal phosphorus uptake or effects on expression of plant phosphate transporter genes. New Phytol. 181, 938-949. doi: 10.1111/j.1469-8137.2008.02720.x

Grunwald, U., Guo, W., Fischer, K., Isayenkov, S., Ludwig-Müller, J., Hause, B., et al. (2009). Overlapping expression patterns and differential transcript levels of phosphate transporter genes in arbuscular mycorrhizal, Pi-fertilised and phytohormone-treated Medicago truncatula roots. Planta 229, 1023-1034. doi: 10.1007/s00425-008-0877-z

Gu, M., Chen, A., Dai, X., Liu, W., and Xu, G. (2011). How does phosphate status influence the development of the arbuscular mycorrhizal symbiosis? Plant Signal. Behav. 6, 1300-1304. doi: 10.4161/psb.6.9.16365

$\mathrm{Gu}$, M., Chen, A., Sun, S., and Xu, G. (2016). Complex regulation of plant phosphate transporters and the gap between molecular mechanisms and practical application: what are missing? Mol. Plant 7, 396-416. doi: 10.1016/j.molp.2015.12.012

Güimil, S., Chang, H. S., Zhu, T., Sesma, A., Osbourn, A., Roux, et al. (2005). Comparative transcriptomics of rice reveals an ancient pattern of response to microbial colonization. Proc. Natl. Acad. Sci. U.S.A. 31, 8066-8070. doi: 10.1073/pnas.0502999102

Guo, B., Irigoyen, S., Fowler, T. B., and Versaw, W. K. (2008a). Differential expression and phylogenetic analysis suggest specialization of plastidlocalized members of the PHT4 phosphate transporter family for 
photosynthetic and heterotrophic tissues. Plant Signal. Behav. 3, 784-790. doi: 10.4161/psb.3.10.6666

Guo, B., Jin, Y., Wussler, C., Blancaflor, E. B., Motes, C. M., and Versaw, W. K. (2008b). Functional analysis of the Arabidopsis PHT4 family of intracellular phosphate transporters. New Phytol. 177, 889-898. doi: 10.1111/j.14698137.2007.02331.x

Guo, C., Guo, L., Li, X., Gu, J., Zhao, M., Duan, W., et al. (2014). TaPT2, a high-affinity phosphate transporter gene in wheat (Triticum aestivum L.), is crucial in plant Pi uptake under phosphorus deprivation. Acta Physiol. Plant. 36, 1373-1384. doi: 10.1007/s11738-014-1516-x

Guo, C., Zhao, X. L., Liu, X. M., Zhang, L. J., Gu, J. T., Li, X. J., et al. (2013). Function of wheat phosphate transporter gene TaPHT2;1 in Pi translocation and plant growth regulation under replete and limited Pi supply conditions. Planta 237, 1163-1178. doi: 10.1007/s00425-012-1836-2

Haferkamp, I., and Schmitz-Esser, S. (2012). The plant mitochondrial carrier family: functional and evolutionary aspects. Front. Plant Sci. 3:2. doi: 10.3389/fpls.2012.00002

Hamburger, D., Rezzonico, E., MacDonald-Comber Petetot, J., Somerville, C., and Poirier, Y. (2002). Identification and characterization of the Arabidopsis PHO1 gene involved in phosphate loading to the xylem. Plant Cell 14, 889-902. doi: $10.1105 /$ tpc. 000745

Harrison, M. J., Dewbre, G. R., and Liu, J. (2002). A phosphate transporter from Medicago truncatula involved in the acquisition of phosphate released by arbuscular mycorrhizal fungi. Plant Cell 14, 2413-2429. doi: 10.1105/tpc. 004861

Hassler, S., Lemke, L., Jung, B., Möhlmann, T., Krüger, F., Schumacher, K., et al. (2012). Lack of the Golgi phosphate transporter PHT4;6 causes strong developmental defects, constitutively activated disease resistance mechanisms and altered intracellular phosphate compartmentation in Arabidopsis. Plant J. 72, 732-744. doi: 10.1111/j.1365-313X.2012.05106.X

Henry, A., Chopra, S., Clark, D. G., and Lynch, J. P. (2012). Responses to low phosphorus in high and low foliar anthocyanin coleus (Solenostemon scutellarioides) and maize (Zea mays). Funct. Plant Biol. 39, 255-265. doi: 10.1071/FP11256

Hinsinger, P. (2001). Bioavailability of soil inorganic $\mathrm{P}$ in the rhizosphere as affected by root-induced chemical changes: a review. Plant Soil 237, 173-195. doi: 10.1023/A:1013351617532

Hirsch, J., Marin, E., Floriani, M., Chiarenza, S., Richaud, P., Nussaume, L., et al. (2006). Phosphate deficiency promotes modification of iron distribution in Arabidopsis plants. Biochimie 88, 1767-1771. doi: 10.1016/j.biochi.2006. 05.007

Hong, J. J., Park, Y. S., Bravo, A., Bhattaraim, K. K., Daniels, D. A., and Harrison, M. A. (2012). Diversity of morphology and function in arbuscular mycorrhizal symbioses in Brachypodium distachyon. Planta 236, 851-865. doi: 10.1007/s00425-012-1677-z

Huang, C. Y., Shirley, N., Genc, Y., Shi, B., and Langridge, P. (2011). Phosphate utilization efficiency correlates with expression of low-affinity phosphate transporters and noncoding RNA, IPS1, in barley. Plant Physiol. 156, 12171229. doi: $10.1104 /$ pp.111.178459

Inoue, Y., Kobae, Y., Omoto, E., Tanaka, A., Banba, M., Takai, S., et al. (2014). The soybean mycorrhiza-inducible phosphate transporter gene, GmPT7, also shows localized expression at the tips of vein endings of senescent leaves. Plant Cell Physiol. 55, 2102-2111. doi: 10.1093/pcp/pcu138

Irigoyen, S., Karlsson, P. M., Kuruvilla, J., Spetea, C., and Versaw, W. K. (2011). The sink-specific plastidic phosphate transporter PHT4;2 influences starch accumulation and leaf size in Arabidopsis. Plant Physiol. 157, 1765-1777. doi: $10.1104 /$ pp.111.181925

Ito, S., Nozoye, T., Sasaki, E., Imai, M., Shiwa, Y., Shibata-Hatta, M., et al. (2015). Strigolactone regulates anthocyanin accumulation, acid phosphatases production and plant growth under low phosphate condition in Arabidopsis. PLoS ONE 10:e0119724. doi: 10.1371/journal.pone.0119724

Javot, H., Penmetsa, R. V., Terzaghi, N., Cook, D. R., and Harrison, M. J. A. (2007a). Medicago truncatula phosphate transporter indispensable for the arbuscular mycorrhizal symbiosis. Proc. Natl. Acad. Sci. U.S.A. 104, 1720-1725. doi: 10.1073/pnas.0608136104

Javot, H., Pumplin, N., and Harrison, M. J. (2007b). Phosphate in the arbuscular mycorrhizal symbiosis: transport properties and regulatory roles. Plant Cell Environ. 30, 310-322. doi: 10.1111/j.1365-3040.2006.01617.x
Jeffries, P., Gianinazzi, S., Perotto, S., Turnau, K., and Barea, J. S. (2003). The contribution of arbuscular mycorrhizal fungi in sustainable maintenance of plant health and soil fertility. Biol. Fertil. Soils 37, 1-16. doi: 10.1007/s00374002-0546-5

Jia, H., Ren, H., Gu, M., Zhao, J., Sun, S., Zhang, X., et al. (2011). The phosphate transporter gene OsPht1;8 is involved in phosphate homeostasis in rice. Plant Physiol. 156, 1164-1175. doi: 10.1104/pp.111.175240

Kai, M., Masuda, Y., Kikuchi, Y., Osaki, M., and Tadano, T. (1997). Isolation characterization of a eDNA from Catharanthus roseus which is highly homologous with phosphate transporter. Soil Sci. Plant Nutr. 43, 227-235. doi: 10.1080/00380768.1997.10414730

Kai, M., Takazumi, K., Adachi, H., Wasaki, J., Shinano, T., and Osaki, M. (2002). Cloning and characterization of four phosphate transporter cDNAs in tobacco. Plant Sci. 163, 837-846. doi: 10.1016/S0168-9452(02)00233-9

Kammerer, B., Fischer, K., Hilpert, B., Schubert, S., Gutensohn, M., Weber, A., et al. (1998). Molecular characterization of a carbon transporter in plastids from heterotrophic tissues: the glucose 6-phosphate/phosphate antiporter. Plant Cell $10,105-117$.

Karandashov, V., and Bucher, M. (2005). Symbiotic phosphate transport inarbuscular mycorrhizas. Trends Plant Sci. 10, 22-29. doi: 10.1016/ j.tplants.2004.12.003

Karandashov, V., Nagy, R., Wegmüller, S., Amrhein, N., and Bucher, M. (2004). Evolutionary conservation of a phosphate transporter in the arbuscular mycorrhizal symbiosis. Proc. Natl. Acad. Sci. U.S.A. 101, 6285-6290. doi: 10.1073/pnas.0306074101

Kariman, K., Barker, S., Jost, R., Finnegan, P. M., and Tibbett, M. (2016). Sensitivity of jarrah (Eucalyptus marginata) to phosphate, phosphite, and arsenate pulses as influenced by fungal symbiotic associations. Mycorrhiza 26, 401-415. doi: 10.1007/s00572-015-0674-z

Kariman, K., Barker, S. J., Jost, R., Finnegan, P. M., and Tibbett, M. (2014). A novel plant-fungus symbiosis benefits the host without forming mycorrhizal structures. New Phytol. 201, 1413-1422. doi: 10.1111/nph.12600

Karlsson, P. M., Herdean, A., Adolfsson, L., Beebo, A., Nziengui, H., Irigoyen, S., et al. (2015). The Arabidopsis thylakoid transporter PHT4;1 influences phosphate availability for ATP synthesis and plant growth. Plant J. 84, 99-110. doi: $10.1111 /$ tpj. 12962

Karthikeyan, A. S., Varadarajan, D. K., Mukatira, U. T., D’Urzo, M. P., Damsz, B., and Raghothama, K. G. (2002). Regulated expression of Arabidopsis phosphate transporters. Plant Physiol. 130, 221-233. doi: 10.1104/pp. 020007

Khan, G. A., Bouraine, S., Wege, S., Li, Y. Y., de Carbonnel, M., Berthomieu, P., et al. (2014). Coordination between zinc and phosphate homeostasis involves the transcription factor PHR1, the phosphate 1 exporter PHO1, and its 2 homologue $\mathrm{PHO} 1 ; \mathrm{H} 3$ in Arabidopsis. J. Exp. Bot. 65, 871-884. doi: $10.1093 / \mathrm{jxb} / \mathrm{ert} 444$

Knappe, S., Flügge, U. I., and Fischer, K. (2003). Analysis of the plastidic phosphate translocator (PT) gene family in Arabidopsis and identification of new PThomologous transporters, classified by their putative substrate binding site. Plant Physiol. 131, 1178-1190. doi: 10.1104/pp.016519

Kobea, Y., and Hata, S. (2010). Dynamics of periarbuscular membranes visualized with a fluorescent phosphate transporter in arbuscular mycorrhizal roots of rice. Plant Cell Physiol. 51, 341-353. doi: 10.1093/pcp/pcq013

Krouk, G., Lacombe, B., Bielach, A., Perrine-Walker, F., Malinska, K., Mounier, E., et al. (2010). Nitrate-regulated auxin transport by NRT1.1 defines a mechanism for nutrient sensing in plants. Dev. Cell 18, 927-937. doi: 10.1016/j.devcel.2010.05.008

Lagarde, B., Basset, M., Lepetit, M., Conejero, G., Gaymart, F., Astruc, S., et al. (1996). Tissue-specific expression of Arabidopsis AKT1 gene is consistent with a role of $\mathrm{K}+$ nutrition. Plant J. 9, 195-200. doi: 10.1046/j.1365313X.1996.09020195.x

Lambers, H., Ahmedi, I., Berkowitz, O., Dunne, C., Finnegan, P. M., Hardy, G. E. S. J., et al. (2013). Phosphorus nutrition of phosphorus-sensitive Australian native plants: threats to plant communities in a global biodiversity hotspot. Conserv. Physiol. 1, 1-21. doi: 10.1093/conphys/cot010

Lambers, H., Shane, M. W., Cramer, M. D., Pearse, S. J., and Veneklaas, E. J. (2006). Root structure and functioning for efficient acquisition of phosphorus: matching morphological and physiological traits. Ann. Bot. 98, 693-713. doi: 10.1093/aob/mcl114 
Lapis-Gaza, H. R., Jost, R., and Finnegan, P. M. (2014). Arabidopsis PHOSPHATE TRANSPORTER1 genes PHT1;8 and PHT1;9 are involved in root-toshoot translocation of orthophosphate. BMC Plant Biol. 14:334-353. doi: 10.1186/s12870-014-0334-z

Lau, T. C., and Stephenson, A. G. (1994). Effects of soil phosphorus on pollen production, pollen size, pollen phosphorus content, and ability to sire seeds in Cucurbita pepo (Cucurbitaceae). Sex. Plant Reprod. 7, 215-220.

Leggewie, G., Willmitzer, L., and Riesmeier, J. W. (1997). Two cDNAs from potato are able to complement a phosphate uptake-deficient yeast mutant: identification of phosphate transporters from higher plants. Plant Cell 9, 381392. doi: $10.2307 / 3870489$

Li, H., Culligan, K., Dixon, R., and Chory, J. (1995). CUE1: a mesophyll Cell specific postitive regulator of light controlled gene expression in Arabidopsis. Plant Cell 7, 1599-1610. doi: 10.1105/tpc.7.10.1599

Li, Y. T., Zhang, J., Zhang, X., Fan, H. M., Gu, M., Qu, H. Y., et al. (2015). Phosphate transporter OsPht1;8 in rice plays an important role in phosphorus redistribution from source to sink organs and allocation between embryo and endosperm of seeds. Plant Sci. 230, 23-32. doi: 10.1016/j.plantsci.2014.10.001

Lima, J. E., Kojima, S., Takahashi, H., and von Wirén, N. (2010). Ammonium triggers lateral root branching in Arabidopsis in an AMMONIUM TRANSPORTER1;3-dependent manner. Plant Cell 22, 3621-3633. doi: $10.1105 /$ tpc. 110.076216

Lin, S. I., Santi, C., Jobet, E., Lacut, E., El Kholti, N., Karlowski, W. M., et al. (2010). Complex regulation of two target genes encoding SPX-MFS proteins by rice mi827 in response to phosphate starvation. Plant Cell Physiol. 51, 2110-2131. doi: $10.1093 /$ pcp/pcq170

Liu, C., Muchhal, U. S., Uthappa, M., Kononowicz, A. K., and Raghothama, K. G. (1998). Tomato phosphate transporter genes are differentially regulated in plant tissues by phosphorus. Plant Physiol. 116, 91-99. doi: 10.1104/pp.116.1.91

Liu, F., Chang, X. J., Ye, Y., Xie, W. B., Wu, P., and Lian, X. M. (2011). Comprehensive sequence and whole-life-cycle expression profile analysis of the phosphate transporter gene family in rice. Mol. Plant 4, 1105-1122. doi: $10.1093 / \mathrm{mp} / \mathrm{ssr} 058$

Liu, F., Wang, Z., Ren, H., Shen, C., Li, Y., Ling, H. Q., et al. (2010). OsSPX1 suppresses the function of OsPHR2 in the regulation of expression of OsPT2 and phosphate homeostasis in shoots of rice. Plant J. 62, 508-517. doi: 10.1111/j.1365-313X.2010.04170.x

Liu, F., Xu, Y., Jiang, H., Jiang, C., Du, Y., Gong, C., et al. (2016). Systematic identification, evolution and expression analysis of the Zea mays PHT1 gene family reveals several new members involved in root colonization by arbuscular mycorrhizal fungi. Int. J. Mol. Sci. 17:E930. doi: 10.3390/ijms17060930

Liu, H., Trieu, A. T., Blaylock, L. A., and Harrison, M. J. (1998). Cloning and characterization of two phosphate transporters from Medicago truncatula roots: regulation in response to phosphate and to colonization by arbuscular mycorrhizal (AM) fungi. Mol. Plant Microbe Interact. 11, 14-22. doi: 10.1094/MPMI.1998.11.1.14

Liu, J., Uhde-Stone, C., Li, A., Vance, C., and Allan, D. (2001). A phosphate transporter with enhanced expression in proteoid roots of white lupin (Lupinus albus L.). Plant Soil 237, 257-266. doi: 10.1023/A:1013396825577

Liu, J., Versaw, W. K., Pumplin, N., Gomez, S. K., Blaylock, L. A., and Harrison, M. J. (2008). Closely related members of the Medicago truncatula PHT1 phosphate transporter gene family encode phosphate transporters with distinct biochemical activities. J. Biol. Chem. 5, 24673-24681. doi: 10.1074/jbc.M802695200

Liu, J., Yang, L., Luan, M., Wang, Y., Zhang, C., Zhang, B., et al. (2015). A vacuolar phosphate transporter essential for phosphate homeostasis in Arabidopsis. Proc. Natl. Acad. Sci. U.S.A. 112, 6571-6578. doi: 10.1073/pnas.1514598112

Liu, P., Chen, S., Song, A., Zhao, S., Fang, W., Guan, Z., et al. (2014). A putative high affinity phosphate transporter, CmPT1, enhances tolerance to Pi deficiency of chrysanthemum. BMC Plant Biol. 14:18. doi: 10.1186/1471-2229-14-18

Liu, T., Huang, T. K., Yang, S. Y., Hong, Y. T., Huang, S. M., Wang, F. N., et al. (2016). Identification of plant vacuolar transporters mediating phosphate storage. Nat. Commun. 3, 1-11. doi: 10.1038/ncomms11095

Liu, T. Y., Huang, T. K., Tseng, C. Y., Lai, Y. S., Lin, S. I., Lin, W. Y., et al. (2012). $\mathrm{PHO} 2$-dependent degradation of PHO1 modulates phosphate homeostasis in Arabidopsis. Plant Cell 24, 2168-2183. doi: 10.1105/tpc.112.096636

Liu, X. M., Zhao, X. L., Zhang, L. J., Lu, W. J., Li, X. J., and Xiao, K. (2013). TaPht1;4, a high-affinity phosphate transporter gene in wheat (Triticum aestivum L.), plays an important role in plant phosphate acquisition under phosphorus deprivation. Funct. Plant Biol. 40, 329-341. doi: 10.1071/FP12242

López-Arredondo, D. L., Leyva-González, M. A., González-Morales, S. I., LópezBucio, J., and Herrera-Estrella, L. (2014). Phosphate nutrition: improving low-phosphate tolerance in crops. Annu. Rev. Plant Physiol. 65, 95-123. doi: 10.1146/annurev-arplant-050213-035949

Lorenz, A., Lorenz, M., Vothknecht, U. C., Niopek-Witz, S., Neuhaus, H. E., and Haferkamp, I. (2015). In vitro analyses of mitochondrial ATP/phosphate carriers from Arabidopsis thaliana revealed unexpected Ca2+- effects. BMC Plant Biol. 15:238-245. doi: 10.1186/s12870-015-0616-0

Loth-Pereda, V., Orsini, E., Courty, P. E., Lota, F., Kohler, A., Diss, L., et al. (2011). Structure and expression profile of the phosphate Pht1 transporter gene family in mycorrhizal Populus trichocarpa. Plant Physiol. 156, 2141-2154. doi: 10.1104/pp.111.180646

Maeda, D., Ashida, K., Iguchi, K., Chechetka, S. A., Hijikata, A., Okusako, Y., et al. (2006). Knockdown of an arbuscular mycorrhiza-inducible phosphate transporter gene of Lotus japonicus suppresses mutualistic symbiosis. Plant Cell Physiol. 47, 807-817. doi: 10.1093/pcp/pcj069

Miao, J., Sun, J., Liu, D., Li, B., Zhang, A., Li, Z., et al. (2009). Characterization of the promoter of phosphate transporter TaPHT1.2 differentially expressed in wheat varieties. J. Gen. Genomics 36, 455-466. doi: 10.1016/S1673-8527(08)60135-6

Mirfakhraei, B. (2014). Phosphorus Acquisition and Allocation Patters in Species of Hakea follow Phylogenetic Relationship under High Phosphorus Supply, But not Low Phosphorus Supply. Master of Science in Agriculture Research School of Plant Biology Faculty of Science, The University of Western Australia, School of Plan Biology. Available at: http://researchrepository.uwa.edu.au/files/3369319/Mirfakhraei_Bahram_2014.pdf

Misson, J., Thibaud, M. C., Bechtold, N., Raghothama, K., and Nussaume, L. (2004). Transcriptional regulation and functional properties of Arabidopsis Pht1;4, a high affinity transporter contributing greatly to phosphate uptake in phosphate deprived plants. Plant Mol. Biol. 55, 727-741. doi: 10.1007/s11103004-1965-5

Miyaji, T., Kuromori, T., Takeuchi, Y., Yamaji, N., Yokosho, K., Shimazawa, A., et al. (2015). AtPHT4;4 is a chloroplast-localized ascorbate transporter in Arabidopsis. Nat. Commun. 5, 5928. doi: 10.1038/ncomms6928

Monné, M., Miniero, D. V., Obata, T., Daddabbo, L., Palmieri, L., Vozza, A., et al. (2015). Functional characterization and organ distribution of three mitochondrial ATP-Mg/Pi carriers in Arabidopsis thaliana. Biochim. Biophys. Acta 1847, 1220-1230. doi: 10.1016/j.bbabio.2015.06.015

Muchhal, U. S., Pardo, J. M., and Raghothama, K. G. (1996). Phosphate transporters from the higher plant Arabidopsis thaliana (ion uptake/yeast complementation). Proc. Natl. Acad. Sci. U.S.A. 93, 10519-10523.

Mudge, S. R., Rae, A. L., Diatloff, E., and Smith, F. W. (2002). Expression analysis suggests novel roles for members of the Pht l family of phosphate transporters in Arabidopsis. Plant J. 31, 341-353. doi: 10.1046/j.1365-313X.2002. 01356.x

Nagai, M., Ohnishi, M., Uehara, T., Yamagami, M., Miura, E., Kamakura, M., et al. (2013). Ion gradients in xylem exudate and guttation fluid related to tissue ion levels along primary leaves of barley. Plant Cell Environ. 36, 1826-1837. doi: 10.1111/pce. 12090

Nagarajan, V. K., Jain, A., Poling, M. D., Lewis, A. J., Raghothama, K. G., and Smith, A. P. (2011). Arabidopsis Pht1;5 mobilizes phosphate between source and sink organs and influences the interaction between phosphate homeostasis and ethylene signaling. Plant Physiol. 156, 1149-1163. doi: 10.1104/pp.111. 174805

Nagy, R., Karandashov, V., Chague, V., Kalinkevich, K., Tamasloukht, M., Xu, G., et al. (2005). The characterization of novel mycorrhiza-specific phosphate transporters from Lycopersicon esculentum and Solanum tuberosum uncovers functional redundancy in symbiotic phosphate transport in solanaceous species. Plant J. 42, 236-250. doi: 10.1111/j.1365-313X.2005.02364.x

Nagy, R., Vasconcelos, M., Zhao, S., McElver, J., Bruce, W., Amrhein, N., et al. (2006). Differential regulation of five Phtl phosphate transporters from maize (Zea mays L.). Plant Biol. 8, 186-197. doi: 10.1055/s-2005873052

Nakamori, K., Takabatake, R., Umehara, Y., Kouchi, H., Izui, K., and Hata, S. (2002). Cloning, functional expression, and mutational analysis of a cDNA for Lotus japonicus mitochondrial phosphate transporter. Plant Cell Physiol. 43, 1250-1253. doi: 10.1093/pcp/pcf141 
Nazoa, P., Vidmar, J. J., Tranbarger, T. J., Mouline, K., Damiani, I., Tillard, P., et al. (2003). Regulation of the nitrate transporter gene AtNRT2.1 in Arabidopsis thaliana: responses to nitrate, amino acids and developmental stage. Plant Mol. Biol. 52, 689-703. doi: 10.1023/A:1024899808018

Niewiadomski, P., Knappe, S., Geimer, S., Fischer, K., and Schulz, B. (2005). The Arabidopsis plastidic glucose 6- phosphate/phosphate translocator GPT1 is essential for pollen maturation and embryo sac development. Plant Cell 17, 760-775. doi: 10.1105/tpc.104.029124

Nussaume, L., Kanno, S., Javot, H., Marin, E., Pochon, N., Ayadi, A., et al. (2011). Phosphate import in plants: focus on the PHT1 transporters. Front. Plant Sci. 30:83. doi: 10.3389/fpls.2011.00083

Nussaume, L., Maréchal, E., Thibaud, M. C., and Block, M. A. (2010). Plant plasma membrane and phosphate deprivation. Plant Cell Monogr. 19, 237-251. doi: 10.1007/978-3-642-13431

Omasits, U., Ahrens, C. H., Müller, S., and Wollscheid, B. (2014). Protter interactive protein feature visualization and integration with experimental proteomic data. Bioinformatics 30, 884-886. doi: 10.1093/bioinformatics/btt607

Paszkowski, U., Kroken, S., Roux, C., and Briggs, S. P. (2002). Rice phosphate transporters include an evolutionarily divergent gene specifically activated in arbuscular mycorrhizal symbiosis. Proc. Natl. Acad. Sci. U.S.A. 99, $13324-$ 13329. doi: 10.1073/pnas.202474599

Pavón, L. R., Lundh, F., Lundin, B., Mishra, A., Persson, B. L., and Spetea, C. (2008). Arabidopsis ANTR1 is a thylakoid $\mathrm{Na}^{+}$-dependent phosphate transporter: functional characterization in Escherichia coli. J. Biol. Chem. 283, 13520-13527. doi: 10.1074/jbc.M709371200

Pedersen, B. P., Kumar, H., Waight, A. B., Risenmay, A. J., Roe-Zurz, Z., Chau, B. H., et al. (2013). Crystal structure of a eukaryotic phosphate transporter. Nature 496, 533-538. doi: 10.1038/nature12042

Péret, B., Clément, M., Nussaume, L., and Desnos, T. (2011). Root developmental adaptation to phosphate starvation: better safe than sorry. Trends Plant Sci. 16, 442-450. doi: 10.1016/j.tplants.2011.05.006

Péret, B., Desnos, T., Jost, R., Kanno, S., Berkowitz, O., and Nussaume, L. (2014). Root architecture responses: in search of phosphate. Plant Physiol. 166, 17131723. doi: 10.1104/pp.114.244541

Pilot, G., Stransky, H., Bushey, D. E., Pratelli, R., Ludwig, U., Wingate, P. M., et al. (2004). Overexpression of GLUTAMINE DUMPER1 leads to hypersecretion of glutamine from hydathodes of Arabidopsis leaves. Plant Cell 16, 1827-1840. doi: 10.1105/tpc.021642

Poirier, Y., and Bucher, M. (2002). Phosphate transport and homeostasis in Arabidopsis. Arabidopsis Book 1:e0024. doi: 10.1199/tab.0024

Poirier, Y., Thoma, S., Somerville, C., and Schiefelbein, J. (1991). A mutant of Arabidopsis deficient in xylem loading of phosphate. Plant Physiol. 97, 10871093. doi: 10.1104/pp.97.3.1087

Popova, Y., Thayumanavana, P., Lonatia, E., Agrochão, M., and Theveleina, J. M. (2010). Transport and signaling through the phosphate-binding site of the yeast Pho84 phosphate transceptor. Proc. Natl. Acad. Sci. U.S.A. 107, 2890-2895. doi: 10.1073/pnas.0906546107

Poulsen, K. H., Nagy, R., Gao, L. L., Smith, S. E., Bucher, M., Smith, F. A., et al. (2005). Physiological and molecular evidence for Pi uptake via the symbiotic pathway in a reduced mycorrhizal colonization mutant in tomato associated with a compatible fungus. New Phytol. 168, 445-454. doi: 10.1111/j.14698137.2005.01523.x

Pratt, J., Boisson, A. M., Gout, E., Bligny, R., Douce, R., and Aubert, S. (2009). Phosphate $(\mathrm{Pi})$ starvation effect on the cytosolic $\mathrm{Pi}$ concentration and $\mathrm{Pi}$ exchanges across the tonoplast in plant cells: an in vivo 31P-nuclear magnetic resonance study using methylphosphonate as a Pi analog. Plant Physiol. 151, 1646-1657. doi: 10.1104/pp.109.144626

Preuss, C. P., Huang, C. Y., Gilliham, M., and Tyerman, S. D. (2010). Channellike characteristics of the low-affinity barley phosphate transporter PHT1;6 when expressed in Xenopus oocytes. Plant Physiol. 152, 1431-1441. doi: 10.1104/pp.109.152009

Preuss, C. P., Huang, C. Y., and Tyerman, S. D. (2011). Proton-coupled highaffinity phosphate transport revealed from heterologous characterization in Xenopus of barley-root plasma membrane transporter, HvPHT1;12. Plant Cell Environ. 34, 681-689. doi: 10.1111/j.1365-3040.2010. 02272.x

Qin, L., Guo, Y., Chen, L., Liang, R., Gu, M., Xu, G., et al. (2012a). Functional characterization of 14 Pht1 family genes in yeast and their expressions in response to nutrient starvation in soybean. PLOS ONE 7:e47726. doi: 10.1371/journal.pone.0047726

Qin, L., Guo, Y., Chen, L., Liang, R., Gu, M., Xu, G., et al. (2012b). The high-affinity phosphate transporter GmPT5 regulates phosphate transport to nodules and nodulation in soybean. Plant Physiol. 159, 1634-1643. doi: 10.1104/pp.112.199786

Rae, A. L., Cybinski, D. H., Jarmey, J. M., and Smith, F. W. (2003). Characterization of two phos-phate transporters from barley; evidence for diverse function and kinetic properties among members of the Pht1 family. Plant Mol. Biol. 53, 27-36. doi: 10.1023/B:PLAN.0000009259.75314.15

Raghothama, K. G. (1999). Phosphate acquisition. Annu. Rev. Plant Physiol. Plant Mol. Biol. 50, 665-693. doi: 10.1146/annurev.arplant.50.1.665

Rausch, C., and Bucher, M. (2002). Molecular mechanisms of phosphate transport in plants. Planta 21, 23-37. doi: 10.1007/s00425-002-0921-3

Rausch, C., Daram, P., Brunner, S., Jansa, J., Laloi, M., Leggewie, G., et al. (2001). A phosphate transporter expressed in arbuscule-containing cells in potato. Nature 414, 462-470. doi: 10.1038/35106601

Rausch, C., Zimmermann, P., Amrhein, N., and Bucher, M. (2004). Expression analysis suggests novel roles for the plastidic phosphate transporter Pht2;1 in auto- and heterotrophic tissues in potato and Arabidopsis. Plant J. 39, 13-28. doi: 10.1111/j.1365-313X.2004.02106.x

Reimer, R. J., and Edwards, R. H. (2004). Organic anion transport is the primary function of the SLC17/type I phosphate transporter family. Pflugers Archiv 447, 629-635. doi: 10.1007/s00424-003-1087-y

Remy, E., Cabrito, T. R., Batista, R. A., Teixeira, M. C., Sá-Correia, I., and Duque, P. (2012). The Pht1;9 and Pht1;8 transporters mediate inorganic phosphate acquisition by the Arabidopsis thaliana root during phosphorus starvation. New Phytol. 195, 356-371. doi: 10.1111/j.1469-8137.2012.04167.x

Ren, F., Zhao, C. Z., Liu, C. S., Huang, K. L., Guo, Q. Q., Chang, L. L., et al. (2014). A Brassica napus PHT1 phosphate transporter, BnPht1;4, promotes phosphate uptake and affects roots architecture of transgenic Arabidopsis. Plant Mol. Biol. 86, 595-607. doi: 10.1007/s11103-014-0249-y

Richardson, A. E. (1994). "Soil microorganisms and phosphorus availability," in Soil Biota: Management in Sustainable Farming Systems, eds V. V. S. R. Gupta and E. R. Grace (Melbourne, VIC: CSIRO Publishing), 50-62.

Rosewarne, G. M., Barker, S. J., Smith, S. E., Smith, F. A., and Schachtman, D. P. (1999). A Lycopersicon esculentum phosphate transporter (LePT1) involved in phosphorus uptake from a vesicular-arbuscular mycorrhizal fungus. New Phytol. 144, 507-516. doi: 10.1046/j.1469-8137.1999.00536.x

Schachtman, D. P., Reid, R. J., and Ayling, S. M. (1998). Phosphorus uptake by plants: from soil to cell. Plant Physiol. 116, 447-453. doi: 10.1104/pp.116.2.447

Scheible, W. R., and Rojas-Triana, M. (2015). "Sensing, signaling and control of phosphate starvation in plants: molecular players and application," in Annual Plant Reviews: Phosphorus Metabolism in Plants in the Post-genomic Era: From Gene to Ecosystem, Vol. 48, eds W. C. Plaxton and H. Lambers (Hoboken, NJ: John Wiley \& Sons, Inc.).

Schneider, A., Hausler, R., Kolukisaoglu, U., Kunze, R., van der Graaff, E., Schwacke, R., et al. (2002). An Arabidopsis thaliana knock-out mutant of the chloroplast triose phosphate/phosphate translocator is severely compromised only when starch synthesis, but not starch mobilization is abolished. Plant J. 32, 685-699. doi: 10.1046/i.1365-313x.2002.01460.x

Schünmann, P. H., Richardson, A. E., Smith, F. W., and Delhaize, E. (2004a). Characterization of promoter expression patterns derived from the Pht phosphate transporter genes of barley (Hordeum vulgare L.). J. Exp. Bot. 55, 855-865. doi: 10.1093/jxb/erh103

Schünmann, P. H., Richardson, A. E., Vickers, C. E., and Delhaize, E. (2004b). Promoter analysis of the barley Pht1;1 phosphate transporter gene identifies regions controlling root expression and responsiveness to phosphate deprivation. Plant Physiol. 136, 4205-4214. doi: 10.1104/pp.104.045823

Secco, D., Baumann, A., and Poirier, Y. (2010). Characterization of the rice PHO1 gene family reveals a key role for OsPHO1;2 in phosphate homeostasis and the evolution of a distinct clade in dicotyledons. Plant Physiol. 152, 1693-1704. doi: 10.1104/pp.109.149872

Secco, D., Wang, C., Arpat, B. A., Wang, Z., Poirier, Y., Tyerman, S. D., et al. (2012). The emerging importance of the SPX domain-containing proteins in phosphate homeostasis. New Phytol. 193, 842-851. doi: 10.1111/j.1469-8137.2011.04002.x

Seo, H. M., Jung, Y., Song, S., Kim, Y., Kwon, T., Kim, D. H., et al. (2008). Increased expression of OsPT1, a high-affinity phosphate transporter, enhances phosphate 
acquisition in rice. Biotechnol. Lett. 30, 1833-1838. doi: 10.1007/s10529-0089757-7

Shane, M. W., McCully, M. E., and Lambers, H. (2004). Tissue and cellular phosphorus storage during development of phosphorus toxicity in Hakea prostrata (Proteaceae). J. Exp. Bot. 55, 1033-1044. doi: 10.1093/jxb/erh111

Shane, M. W., Stigter, K., Fedosejevs, E. T., and Plaxton, W. C. (2014). Senescenceinducible cell wall and intracellular purple acid phosphatases: implications for phosphorus remobilization in Hakea prostrata (Proteaceae) and Arabidopsis thaliana (Brassicaceae). J. Exp. Bot. 65, 6097-6106. doi: 10.1093/jxb/eru348

Sharma, T., Dreyer, I., and Riedelsberger, J. (2013). The role of $\mathrm{K}^{+}$channels in uptake and redistribution of potassium in the model plant Arabidopsis thaliana. Front. Plant Sci. 4:224. doi: 10.3389/fpls.2013.00224

Shi, S., Wang, D., Yan, Y., Zhang, F., Wang, H., Gu, M., et al. (2013). Function of phosphate transporter OsPHT2; 1 in improving phosphate utilization in rice. Chin. J. Rice Sci. 27, 457-465. doi: 10.3969/j.issn.1001-7216.2013.05.002

Shibagaki, N., Rose, A., McDermott, J. P., Fujiwara, T., Hayashi, H., Yoneyama, T., et al. (2002). Selenate-resistant mutants of Arabidopsis thaliana identify Sultr1; 2 , a sulfate transporter required for efficient transport of sulfate into roots. Plant J. 29, 475-486. doi: 10.1046/j.0960-7412.2001.01232.x

Shin, H., Shin, H. S., Dewbre, G. R., and Harrison, M. J. (2004). Phosphate transport in Arabidopsis: Pht1;1 and Pht1; 4 play a major role in phosphate acquisition from both low- and high-phosphate environments. Plant J. 39, 629-642. doi: 10.1111/j.1365-313X.2004.02161.X

Shu, B., Xia, R. X., and Wang, P. (2012). Differential regulation of Pht1 phosphate transporters from trifoliate orange (Poncirus trifoliata L. Raf) seedlings. Sci. Hortic. 146, 115-123. doi: 10.1016/j.scienta.2012.08.014

Siebers, M., Dörmann, P., and Hölzl, G. (2015). Membrane remodelling in phosphorus-deficient plants. Ann. Plant Rev. 48, 237-263. doi: 10.1002/9781118958841.ch9

Sisaphaithong, T., Kondo, D., Matsunaga, H., Kobae, Y., and Hata, S. (2012). Expression of plant genes for arbuscular mycorrhiza-inducible phosphate transporters and fungal vesicle formation in sorghum, barley, and wheat roots. Biosci. Biotechnol. Biochem. 76, 2364-2367. doi: 10.1271/bbb.120782

Smith, A. P., Nagarajan, K. V., and Raghothama, K. G. (2011). Arabidopsis Pht1;5 plays an integral role in phosphate homeostasis. Plant Signal. Behav. 6, 16761678. doi: $10.4161 /$ psb.6.11.17906

Smith, F. W., Cybinski, D., and Rea, A. L. (1999). "Regulation of expression of genes encoding phosphate transporters in barley roots," in Plant Nutrition: Molecular Biology and Genetics, eds A. Jensen and G. Gissel-Nielsen (Dordrecht: Kluwer Academic Publishers), 145-150.

Smith, F. W., Mudge, S. R., Rae, A. L., and Glassop, D. (2003). Phosphate transport in plants. Plant Soil 248, 71-83. doi: 10.1023/A:1022376332180

Smith, S. E., and Smith, F. A. (2012). Fresh perspectives on the roles of arbuscular mycorrhizal fungi in plant nutrition and growth. Mycologia 104, 1-13. doi: 10.3852/11-229

Stappen, R., and Krämer, R. (1994). Kinetic mechanism of phosphate/phosphate and phosphate/OH- antiports catalyzed by reconstituted phosphate carrier from beef heart mitochondria. J. Biol. Chem. 269, 11240-11246.

Stefanovic, A., Arpat, A. B., Bligny, R., Gout, E., Vidoudez, C., Bensimon, M., et al. (2011). Over-expression of PHO1 in Arabidopsis leaves reveals its role in mediating phosphate efflux. Plant J. 66, 689-699. doi: 10.1111/j.1365313X.2011.04532.x

Stefanovic, A., Ribot, C., Rouached, H., Wang, Y., Chong, J., Belbahri, L., et al. (2007). Members of the PHO1 gene family show limited functional redundancy in phosphate transfer to the shoot, and are regulated by phosphate deficiency via distinct pathways. Plant J. 50, 982-994. doi: 10.1111/j.1365-313X.2007.03108.x

Streatfield, S. J., Weber, A., Kinsman, E. A., Hausler, R. E., and Li, J. M. (1999). The phosphoenolpyruvate/phosphate translocator is required for phenolic metabolism, palisade cell development, and plastid-dependent nuclear gene expression. Plant Cell 11, 1609-1621. doi: 10.1105/tpc.11.9.1609

Sun, S. B., Gu, M., Cao, Y., Huang, X. P., Zhang, X., Ai, P. H., et al. (2012). A constitutive expressed phosphate transporter, OsPht1;1, modulates phosphate uptake and translocation in phosphate-replete rice. Plant Physiol. 159, 1571-1581. doi: 10.1104/pp.112.196345

Takabatake, R., Hata, S., Taniguchi, M., Kouchi, H., Sugiyama, T., and Izui, K. (1999). Isolation and characterization of cDNAs encoding mitochondrial phosphate transporters in soybean, maize, rice, and Arabidopsis. Plant Mol. Biol. 40, 479-486. doi: 10.1023/A:1006285009435
Takahashi, H., Watanabe, A. T., Smith, F., Blake-kalff, M., Hawkesford, M., and Saito, K. (2000). The roles of three functional transporters involved in uptake and translocation of sulphate in Arabidopsis thaliana. Plant J. 23, 171-182. doi: 10.1046/j.1365-313x.2000.00768.x

Tamura, Y., Kobae, Y., Mizuno, T., and Hata, S. (2012). Identification and expression analysis of arbuscular mycorrhiza-inducible phosphate transporter genes of soybean. Biosci. Biotechnol. Biochem. 76, 309-313. doi: 10.1271/bbb.110684

Tian, H., Drijber, R. A., Li, X., Miller, D. N., and Wienhold, B. J. (2013). Arbuscular mycorrhizal fungi differ in their ability to regulate the expression of phosphate transporters in maize (Zea mays L.). Mycorrhiza 23, 507-514. doi: 10.1007/s00572-013-0491-1

Tian, J., Venkatachalam, P., Liao, H., Yan, X., and Raghothama, K. (2007). Molecular cloning and characterization of phosphorus starvation responsive genes in common bean (Phaseolus vulgaris L.). Planta 227, 151-165. doi: 10.1007/s00425-007-0603-2

Tittarelli, A., Milla, L., Vargas, F., Morales, A., Neupert, C., Meisel, L., et al. (2007). Isolation and comparative analysis of the wheat TaPT2 promoter: identification in silico of new putative regulatory motifs conserved between monocots and dicots. J. Exp. Bot. 58, 2573-2582. doi: 10.1093/jxb/erm123

Toyota, K., Tamura, M., Ohdan, T., and Nakamura, Y. (2006). Expression profiling of starch metabolism-related plastidic translocator genes in rice. Planta 223, 248-257. doi: 10.1007/s00425-005-0128-5

Ullrich-Eberius, C. I., Novacky, A., Fischer, E., and Lüttge, U. (1981). Relationship between energy-dependent phosphate uptake and the electrical membrane potential in Lemna gibba G1. Plant Physiol. 67, 797-801. doi: 10.1104/pp.67.4.797

Vance, C. P. (2008). "Plants without arbuscular mycorrhizae," in The Ecophysiology of Plant-Phosphorus Interactions, eds P. J. White and J. P. Hammond (Dordrecht: Springer), 117-142.

Versaw, W. K., and Harrison, M. J. (2002). A chloroplast phosphate transporter, PHT2;1, influences allocation of phosphate within the plant and phosphate-starvation responses. Plant Cell 14, 1751-1766. doi: 10.1105/tpc. 002220

Volpe, V., Giovannetti, M., Sun, X. G., Fiorilli, V., and Bonfante, P. (2016). The phosphate transporters LjPT4 and MtPT4 mediate early root responses to phosphate status in non- mycorrhizal roots. Plant Cell Environ. 39, 660-671. doi: $10.1111 /$ pce. 12659

Walder, F., Brulé, D., Koegel, S., Wiemken, A., Boller, T., and Courty, P. E. (2015). Plant phosphorus acquisition in a common mycorrhizal network: regulation of phosphate transporter genes of the Phtl family in sorghum and flax. New Phytol. 205, 1632-1645. doi: 10.1111/nph.13292

Wang, C., Yue, W., Ying, Y., Wang, S., Secco, D., Liu, Y., et al. (2015). OsSPXMFS3, a vacuolar phosphate efflux transporter, is involved in maintaining Pi homeostasis in rice. Plant Physiol. 169, 2822-2831. doi: 10.1104/pp.15. 01005

Wang, G., Shi, J., Battle, S., Zhang, C., and Lu, H. (2011). Circadian clock-regulated phosphate transporter PHT4;1 plays an important role in Arabidopsis defense. Mol. Plant 4, 516-526. doi: 10.1093/mp/ssr016

Wang, G., Zhang, C., Battle, S., and Lu, H. (2014). The phosphate transporter PHT4;1 is a salicylic acid regulator likely controlled by the circadian clock protein CCA1. Front. Plant Sci. 5:701. doi: 10.3389/fpls.2014.00701

Wang, X. F., Wang, Y. F., Piñeros, M. A., Wang, Z. Y., Wang, W. X., Li, C. Y., et al. (2014). Phosphate transporters OsPHT1; 9 and OsPHT1;10 are involved in phosphate uptake in rice. Plant Cell Environ. 37, 1159-1170. doi: $10.1111 /$ pce. 12224

Wang, Y., Ribot, C., Rezzonico, E., and Poirier, Y. (2004). Structure and expression profile of the Arabidopsis $\mathrm{PHO}$ gene family indicates a broad role in inorganic phosphate homeostasis. Plant Physiol. 135, 400-411. doi: 10.1104/pp.103.037945

Wang, Y. Y., and Tsay, Y. F. (2011). Arabidopsis nitrate transporter NRT1.9 is important in phloem nitrate transport. Plant Cell. 23, 1945-1957.

Weber, A. P. M. (2004). Solute transporters as connecting elements between cytosol and plastid stroma. Curr. Opin. Plant Biol. 7, 247-253. doi: 10.1016/j.pbi.2004.03.008

Weber, A. P. M., and Linka, N. (2011). Connecting the Plastid. Transporters of the plastid envelope and their role in linking plastidal with cytosolic metabolism. Ann. Rev. Plant Biol. 62, 53-77. doi: 10.1146/annurev-arplant-042110-103903 
Weber, A. P. M., Linka, N., and Bhattacharya, D. (2006). Single, ancien origin of a plastid metabolite translocator family in Plantae from an endomembrane derived ancestor. Eycaryot. Cell 5, 609-612. doi: 10.1128/EC.5.3.609612.2006

Wege, S., Khan, G. A., Jung, J. Y., Vogiatzaki, E., Pradervand, S., Aller, I., et al. (2016). The EXS domain of PHO1 participates in the response of shoots to phosphate deficiency via a root-to-shoot signal. Plant Physiol. 170, 385-400. doi: 10.1104/pp.15.00975

Wegmüller, S., Svistoonoff, S., Reinhardt, D., Stuurman, J., Amrhein, N., and Bucher, M. (2008). A transgenic dTph1 insertional mutagenesis system for forward genetics in mycorrhizal phosphate transport of Petunia. Plant J. 54, 1115-1127. doi: 10.1111/j.1365-313X.2008.03474.x

Williams, L. E., and Miller, A. J. (2001). Transporters responsible for the uptake and partitioning of nitrogenous solutes. Annu. Rev. Plant Physiol. Plant Mol. Biol. 52, 659-688. doi: 10.1146/annurev.arplant.52.1.659

Willmann, M., Gerlach, N., Buer, B., Polatajko, A., Nagy, R., Koebke, E., et al. (2013). Mycorrhizal phosphate uptake pathway in maize: vital for growth and cob development on nutrient poor agricultural and greenhouse soils. Front. Plant Sci. 4:533. doi: 10.3389/fpls.2013.00533

Wright, D. P., Scholes, J. D., Read, D. J., and Rolfe, S. A. (2005). European and African maize cultivars differ in their physiological and molecular responses to mycorrhizal infection. New Phytol. 167, 881-896. doi: 10.1111/j.14698137.2005.01472.x

Wu, Z., Zhao, J., Gao, R., Hu, G., Gai, J., Xu, G., et al. (2011). Molecular cloning, characterization and expression analysis of two members of the Pht1 family of phosphate transporters in Glycine max. PLOS ONE 6:e19752. doi: 10.1371/journal.pone.0019752

Xiao, K., Liu, J., Dewbre, G., Harrison, M., and Wang, Z. Y. (2006). Isolation and characterization of root-specific phosphate transporter promoters from Medicago truncatula. Plant Biol. 8, 439-449. doi: 10.1055/s-2005873053

Xie, X. N., Huang, W., Liu, F. C., Tang, N., Liu, Y., Lin, H., et al. (2013). Functional analysis of the novel mycorrhiza-specific phosphate transporter AsPT1 and PHT1 family from Astragalus sinicus during the arbuscular mycorrhizal symbiosis. New Phytol. 198, 836-852. doi: 10.1111/nph.12188

Xu, G. H., Chague, V., Melamed-Bessudo, C., Kapulnik, Y., Jain, A., Raghothama, K. G., et al. (2007). Functional characterization of LePT4: a phosphate transporter in tomato with mycorrhiza-enhanced expression. J. Exp. Bot. 58, 2491-2501. doi: 10.1093/jxb/erm096

Yang, S. Y., Grønlund, M., Jakobsen, I., Grotemeyer, M. S., Rentsch, D., Miyao, A., et al. (2012). Nonredundant regulation of rice arbuscular mycorrhizal symbiosis by two members of the PHOSPHATE TRANSPORTER1 gene family. Plant Cell 24, 4236-4251. doi: 10.1105/tpc.112.104901

Ye, Y., Yuan, J., Chang, X., Yang, M., Zhang, L., Lu, K., et al. (2015). The phosphate transporter gene OsPht1;4 is involved in phosphate homeostasis in rice. PLoS ONE 10:e0126186. doi: 10.1371/journal.pone.0126186

Zhang, F., Sun, Y. F., Pei, W. X., Jain, A., Sun, R., Cao, Y., et al. (2015). Involvement of OsPht1;4 in phosphate acquisition and mobilization facilitates embryo development in rice. Plant J. 82, 556-569. doi: 10.1111/tpj.12804

Zhang, F., Wu, X. N., Zhou, H. M., Wang, D. F., Jiang, T. T., Sun, Y. F., et al. (2014). Overexpression of rice phosphate transporter gene OsPT6 enhances phosphate uptake and accumulation in transgenic rice plants. Plant Soil 384, 259-270. doi: 10.1007/s11104-014-2168-8

Zhang, L., Hu, B., Li, W., Che, R., Deng, K., Li, H., et al. (2014). OsPT2, a phosphate transporter, is involved in the active uptake of selenite in rice. New Phytol. 201, 1183-1191. doi: 10.1111/nph.12596

Zhang, Z., Liao, H., and Lucas, W. J. (2014). Molecular mechanisms underlying phosphate sensing, signaling, and adaptation in plants. J. Integr. Plant Biol. 56, 192-220. doi: 10.1111/jipb.12163

Zhu, W., Miao, Q., Sun, D., Yang, G., Wu, C., Huang, J., et al. (2012). The mitochondrial phosphate transporters modulate plant responses to salt stress via affecting ATP and gibberellin metabolism in Arabidopsis thaliana. PLoS ONE 7:e43530. doi: 10.1371/journal.pone.0043530

Conflict of Interest Statement: The authors declare that the research was conducted in the absence of any commercial or financial relationships that could be construed as a potential conflict of interest.

Copyright (C) 2016 Młodzińska and Zboinska. This is an open-access article distributed under the terms of the Creative Commons Attribution License (CC BY). The use, distribution or reproduction in other forums is permitted, provided the original author(s) or licensor are credited and that the original publication in this journal is cited, in accordance with accepted academic practice. No use, distribution or reproduction is permitted which does not comply with these terms. 